\title{
Desvios na Implementação da Política de Avaliação da Aprendizagem e sua Associação com as Condições de Trabalho na Escola
}

\author{
LYS MARIA VINHAES DANTAS \\ Doutoranda em Educação pela Universidade Federal da Bahia \\ lys.vinhaes@gmail.com
}

\begin{abstract}
Resumo
Este artigo apresenta os principais resultados de uma pesquisa que analisou a implementação da política de Avaliação da Aprendizagem em 163 escolas públicas urbanas situadas em 11 municípios da Bahia, no período 2002-2003. Ao fazê-lo, utilizou o modelo proposto por Lipsky (1980), para quem a burocracia de linha de frente - funcionários públicos em contato direto com o cidadão - cria estratégias de enfrentamento para lidar com as dificuldades e pressões inerentes ao serviço público, alterando as políticas sob sua responsabilidade e dando-lhes o formato final. Em primeiro lugar, foi feito o levantamento da Avaliação da Aprendizagem sob a ótica de seus formuladores (Secretaria da Educação do Estado e Universidade Federal da Bahia) para, em seguida, identificarem-se os desvios do desenho original, a partir dos relatos das escolas. Por fim, verificou-se que, de 48 possibilidades de associação das condições de trabalho às práticas relatadas, apenas 8 tiveram um resultado mediano a forte. Além disso, concluiu-se que as práticas associadas à etapa de aplicação dos instrumentos não provocaram um redesenho da Avaliação da Aprendizagem, mas aquelas relacionadas à fase de planejamento e de utilização dos dados implicaram dificuldades e usos não previstos inicialmente, sendo, portanto, as etapas que merecem maior atenção quando da proposta de novos desenhos de avaliação em larga escala.
\end{abstract}

Palavras-chave: avaliação de sistema educacional, avaliação em larga escala, implementação de política pública.

\begin{abstract}
Resumen
Este artículo presenta los resultados más importantes de una investigación que analizó la implementación de la política de Evaluación del Aprendizaje en 163 escuelas públicas urbanas situadas en 11 municipios del Estado de Bahía, en el período 2002-2003. Para ello, utilizó el modelo propuesto por Michael Lipsky (1980), para quien la burocracia de los funcionarios públicos en contacto directo con el ciudadano, crea estrategias de enfrentamiento para lidiar con las dificultades y presiones inherentes al servicio público, alterando las políticas bajo su responsabilidad y dándoles el formato final. En primer lugar se hizo el relevamiento de la Evaluación del Aprendizaje bajo la óptica de quienes la formularon (Secretaría de Educación del Estado y Universidad Federal de Bahía) para luego, identificar los desvíos del disesño original, a partir de los relatos de las escuelas. Finalmente se verificó que de 48 posibilidades de relacionar las condiciones de trabajo con las prácticas relatadas, apenas 8 tuvieron un resultado de medio a alto. Además, se concluyó que las prácticas relacionadas con la etapa
\end{abstract}


de aplicación de los instrumentos no provocaron una reformulación de la Evaluación del Aprendizaje, pero aquellas relacionadas con la fase de planificación y de utilización de los datos tuvieron dificultades y usos no previstos inicialmente, siendo, por lo tanto, las etapas que merecen mayor atención a la hora de proponer nuevos diseños de Evaluación a gran escala.

Palabras-clave: evaluación del sistema educativo, evaluación a gran escala, implementación de política pública.

\begin{abstract}
This article presents the results of a study that utilized Lipsky's concept of street-level bureaucracy (and the relation between their patterns of practice and work conditions) to analyze the implementation of a state-wide assessment program, from the perspective of 163 public schools situated in 11 municipalities in Bahia, during the 2002-2003 period. To do so, it first compared the official orientation produced by the policy formulators to the patterns of practice these schools reported, and then analyzed the differences between both of them, in order to investigate if the policy had been implemented as originally designed or if the implementation processes had resulted in a new policy. Then it examined the association between the reported patterns and the perception of work conditions. Only eight associations were considered moderate or strong among 48 possibilities, which raises the question as to other reasons why the bureaucrats establish their patterns of practice. Also, the results revealed that the reported practices related to the application of the tests did not change the assessment program's original design, but the practices related to the planning and utilization of the data revealed some difficulties and uses not initially planned by the policy formulators.
\end{abstract}

Key words: educational system assessment program, large-scale evaluation, public policy implementation. 


\section{INTRODUÇÃO}

No Brasil, muitos programas de avaliação de sistemas educacionais têm florescido, nos últimos anos, sem que se façam análises sobre sua implementação e/ou sobre seus resultados. Sendo muito caras, essas políticas $^{1}$ merecem um olhar mais atento que permita avaliar seus processos de implementação, levantando diferenças entre a política real e aquela originalmente formulada, de modo a se investigar até que ponto a avaliação aconteceu como planejada e até que ponto resultou nos fins inicialmente pensados. Estudos nesse sentido podem enriquecer a discussão sobre a avaliação em larga escala e buscar alternativas ao modelo $\mathrm{Saeb}^{2}$, dominante no país.

Em 2001, o governo do Estado da Bahia lançou o projeto ${ }^{3}$ Avaliação da Aprendizagem, dentro do escopo maior do Projeto de Avaliação Externa/Programa Educar para Vencer, com características diversas daquelas mais comumente encontradas nas experiências de avaliação conduzidas no Brasil no período. Esse projeto voltou-se para a avaliação de alunos de $1^{\mathrm{a}}$ a $4^{\mathrm{a}}$ série, de 7 a 10 anos, por meio da aplicação bimensal de provas de lápis e papel, e teve como objetivo instrumentalizar a escola pública para o diagnóstico das dificuldades desses alunos, ao longo das três primeiras unidades do ano letivo. Para que pudessem produzir resultado imediato, a tempo de corrigir as deficiências identificadas, as provas deveriam ser corrigidas pela própria comunidade escolar, a partir de quadros-diagnóstico e guias-diagnóstico. A cada aplicação, a escola deveria encaminhar, à equipe do projeto, um relatório contendo suas reflexões e planos de trabalho, definidos a partir dos resultados encontrados. A síntese

1 Neste trabalho, entende-se um projeto ou um programa de governo como política, como visto em Souza (2002, p.17), para quem programas e projetos do governo são traduções das políticas públicas e sua implementação é "política pública posta em prática [...], transformação da política em ação".

2 O sucesso do Sistema Nacional de Avaliação da Educação Básica - Saeb -, consolidado a partir de 1995, contribuiu para que muitos Estados lançassem suas políticas de avaliação atendendo ao mesmo modelo, caracterizado por provas padronizadas de Língua Portuguesa e Matemática aplicadas, a cada dois anos, a alunos de $4^{\mathrm{a}}$ e $8^{\mathrm{a}}$ séries do Ensino Fundamental e $3^{\circ}$ ano do Ensino Médio, correção centralizada, e resultados encaminhados para o público-alvo vários meses depois da aplicação dos testes. A grande diferença estabelecida entre o modelo Saeb e o adotado pelas outras esferas de governo tem sido relacionada à aplicação censitária (para os Estados e municípios), enquanto o Saeb trabalha com amostras.

3 Esse projeto fez parte do Projeto de Avaliação Externa, desenvolvido pela Secretaria da Educação do Estado da Bahia (SEC) em parceria com a Universidade Federal da Bahia, por intermédio do Centro de Estudos Interdisciplinares para o Setor Público (ISP) e com interveniência da Fundação de Apoio à Pesquisa e à Extensão (Fapex). 
desses relatórios era então encaminhada para as secretarias de educação, com a finalidade de facilitar o apoio às unidades escolares na consecução das ações propostas pelas escolas. Com previsão de expansão gradual, o projeto foi iniciado em 2001 com a aplicação de provas de Língua Portuguesa e Matemática para alunos de $1^{\mathrm{a}}$ e $2^{\mathrm{a}}$ séries matriculados em 1.532 escolas públicas urbanas de 130 municípios. Em 2004, atingiu 2.674 escolas com alunos de $1^{\mathrm{a}}$ a $4^{\mathrm{a}}$ séries, de 273 municípios, além de inserir testes de produção textual para a $3^{\mathrm{a}}$ e $4^{\mathrm{a}}$ séries.

Por seguir um modelo diverso daquele mais comumente utilizado no Brasil, a implementação do projeto de Avaliação da Aprendizagem foi objeto de pesquisa conduzida em nível de mestrado por esta autora ${ }^{4}$. Para a análise de implementação, foi usado o modelo proposto por Lipsky (1980), para quem os verdadeiros formuladores das políticas públicas são aqueles que as implementam, ao adaptarem seu desenho original às condições de trabalho a que são submetidos. Contribuíram para esse estudo 163 escolas urbanas localizadas em 11 municípios baianos, dentre os 273 que fizeram parceria com o Estado em 2004. Os relatórios dessas escolas (654 ao todo), encaminhados ao Projeto de Avaliação Externa ao final de três aplicações de prova em 2002 e outras três em 2003, foram lidos, analisados e categorizados, na busca de resposta às seguintes indagações: os desvios de implementação da Avaliação da Aprendizagem desfiguraram a política como originalmente formulada? É possível entregar-se a implementação da avaliação à unidade avaliada? A unidade escolar conseguiu atuar autonomamente com base nos resultados e de suas análises?

Este artigo apresenta uma síntese da referida pesquisa e de seus resultados. Ao identificar aspectos relacionados ao atendimento dos procedimentos e padrões definidos pelos formuladores de uma política de avaliação externa e ao buscar associações entre os desvios de padrão observados e a percepção das condições de trabalho por professores e diretores envolvidos, pretende-se apresentar informações que contribuam para a definição de novas políticas de avaliação educacional. Para tanto, esse texto foi organizado em seis seções: a primeira é a introdução; a segunda apresenta, brevemente, o cenário atual da avaliação educacional em larga escala e da escola pública; a terceira descreve a política Avaliação da Aprendizagem em seu modelo original, como concebido por seus formuladores; a quarta introduz a metodologia empregada nessa investigação; a quinta seção relaciona os resultados obtidos. Por fim, nas

4 Escola de Administração da Universidade Federal da Bahia, sob orientação do Prof. Robert E. Verhine. 
considerações finais, são apresentas algumas observações julgadas úteis no delineamento de novas políticas de avaliação educacional.

\section{UM BREVE OLHAR SOBRE A AVALIAÇÃO EM LARGA ESCALA E A ESCOLA}

As duas subseções a seguir apresentam, de maneira breve, o panorama no qual se consolidam as abordagens de avaliação dos sistemas educacionais e a escola sobre a qual incidem essas abordagens. É interessante perceber, nesses próximos parágrafos, o caráter regulatório e de controle que cerca as políticas de avaliação e a resistência encontrada nas escolas a esse tipo de ação, em uma situação diversa daquela observada em relação à política de Avaliação da Aprendizagem, na Bahia.

\subsection{O Lugar da Avaliação em Larga Escala no Cenário Atual}

Na América Latina, a partir da década de 1980 e mais intensamente nos anos 1990, foram implantadas reformas educacionais em vários países, dentre eles o Brasil, conforme os contextos politicos dos diferentes países e os antecedentes culturais e históricos da sua administração (Barroso, 2002, p.175). De maneira geral, esses programas políticos estavam e estão atrelados a uma necessidade do Estado de tornar-se mais eficiente, para uma demanda sempre crescente e exigente, com recursos considerados escassos (Boorsma, 1997; Osborne, 1994; Lipsky, 1980). Também responderam a uma demanda geral por maior transparência e responsabilização do poder público quanto a serviços considerados essenciais, como a educação.

$\mathrm{Na}$ área educacional, além da questão geral do Estado citada anteriormente, foi identificada uma crise de qualidade, muitas vezes associada à improdutividade da escola (pedagógica e administrativa). Embora o acesso estivesse garantido para a maior parte da população, os mecanismos de exclusão e discriminação resultavam da ineficiência e ineficácia da escola. Especificamente no Brasil, a crise educacional foi perversamente associada à expansão que garantiu a universalização do acesso (Castro, 1999).

Para dar conta dos problemas resultantes dessa crise, muitos governos acreditaram serem necessárias reformas dos sistemas educacionais, orientadas pela necessidade de introduzir mecanismos que favorecessem e regulassem a qualidade dos seus serviços. As mudanças propostas tiveram ênfase no ensino básico e, em acordo com os demais setores do governo, visaram ao fortalecimento do papel do Ministério da 
Educação como planificador e controlador da politica educacional, bem como a delegação da operacionalização, execução e em grande parte da manutenção do ensino para as unidades subnacionais (Oliveira, 2002, p.70). Para muitos, essa saída do Estado implicou a terceirização da educação. Resumindo-se, tais reformas visaram à descentralização do poder ${ }^{5}$, ao fortalecimento da gestão escolar e ao aumento da autonomia local' ${ }^{6}$ (Sander, 2002; Oliveira, 2002; Molina, 2002).

A sociedade, de modo geral, apoiou a priorização das mudanças na área educacional, especialmente porque a educação foi considerada a porta do futuro. De maneira geral, a melhoria da qualidade da educação foi vista como fonte de competitividade internacional e sinônimo de desenvolvimento auto-sustentado (Corrales, 2000, p. 4). Melhorar o grau de escolaridade passou a ser fator de empregabilidade, e a educação foi considerada um componente para diminuir o grau de desigualdade social e promover a melhoria da distribuição de renda (Castro, 1999, p. 5).

Nesse panorama de reforma de Estado, a avaliação se fortaleceu como ferramenta a serviço da transparência, do monitoramento e do controle, como contrapartida para os processos de descentralização e autonomia local. Essa disciplina, como mencionado por Sander (2002, p. 62), ao permitir a mensuração e comparação do sucesso relativo dos países, das comunidades $e$ das organizações sociais, passou a receber financiamento "generoso" de governos e organismos financeiros, também para o setor de educação. Paralelo a esses movimentos nacionais, organizações internacionais, como a Unesco e a OCDE, vêm incentivando programas de avaliação que envolvem diversas nações, como o TIMMS e o PISA. Organismos financiadores, como o Banco Mundial e o Banco de Desenvolvimento Interamericano, estimulam a criação de atividades de avaliação, de modo geral, e determinam a avaliação de impacto para os programas implementados com os recursos que emprestam. No Brasil, em

5 A consulta à Constituição Brasileira de 1988, à Lei Federal n. 9424/96 que regulamenta o Fundef, e à LDB n. 9394/96, permite que se observe o panorama dessa descentralização no Brasil.

6 É interessante perceber que, paralelo a esse movimento de descentralização, foram implementadas várias políticas centralizadoras no mesmo período, como o lançamento das Diretrizes Curriculares Nacionais e do Saeb. Segundo Oliveira (2002), o aparato de regulação e controle foi centralizado pelo Ministério da Educação (MEC). Os controles em cascata fizeram com que as escolas - apesar de todo o discurso de autonomia - estivessem limitadas à construção de projeto político-pedagógico e de regimento, sendo avaliadas por padrões determinados externamente. Mesmo quando receberam recursos para a administração local, as escolas estiveram (e estão) presas às rubricas do financiador, seja o tesouro do Estado, sejam as agências como o Banco Interamericano de Desenvolvimento ou o Banco Mundial. 
decorrência disso, a década de 90 presenciou um boom de políticas públicas relacionadas à avaliação.

O tema da avaliação, quaisquer que sejam a escala, a natureza ou os objetivos em discussão, é um dos mais controvertidos na área educacional, e a literatura sobre ele freqüentemente está carregada de vieses políticos das correntes dominantes. Por ora, vale registrar que a "terceirização" da educação e o uso da avaliação como ferramenta para sua regulação têm sido alvo de ferozes críticas que fomentam a resistência dos implementadores às políticas avaliativas. Essas críticas e as discussões sobre a impossibilidade de se tratar a educação como "um serviço a ser oferecido a um cliente" não impediram que os sistemas de avaliação em larga escala se consolidassem tanto em nível federal quanto estadual, gradualmente atingindo o nível municipal. A relação entre avaliação, Estado e escola é colocada por Depresbiteris (2001, p. 138): O Estado não pode restringir a autonomia das escolas, mas é imperioso que ele se responsabilize pela qualidade de seus sistemas educativos, nas esferas pública e privada.

Adotar, contudo, políticas de avaliação não é simples. Além das resistências e críticas postas aos mecanismos de reforma do Estado, os gestores dos sistemas educacionais se defrontam com uma série de desafios ao formulá-las e implementa-las ${ }^{7}$. O principal deles está em entender o sistema educacional como uma rede integrada, com parcerias articuladas, e não apenas como um conjunto de escolas sobre as quais um órgão central exerce poder. Qualquer política a ser implementada por meio de tantos e tão diversos integrantes, no mínimo, demanda tempo e articulação, sem mencionar que nem todos eles estão de acordo ou abertos a novas propostas dos formuladores. Esse aspecto é muito importante para a compreensão do uso (ou da ausência dele) que os integrantes do sistema possam vir a fazer dos resultados de uma avaliação externa. Nesse sentido, é necessário lembrar que a avaliação de um determinado sistema deve estar articulada com as demais políticas desse sistema e com as avaliações realizadas pelas outras esferas governamentais, de modo a respeitar as questões legais, a reduzir conflitos na sua implementação e a otimizar sua utilização.

O segundo grande desafio está ligado à busca de solução para questões de implementação e metavaliação. Dentre eles podem ser destacados:

a) A (in)capacidade dos sistemas educacionais de processar, em tempo hábil, a enorme quantidade de informações produzida pela avaliação. Esse exercício demanda dos técnicos e educadores um

7 Para uma discussão sobre limites e desafios da avaliação, consultar Vianna (2001). 
conhecimento profundo dos seus sistemas educacionais e grande articulação entre seus diversos componentes. Nessa lógica, é interessante a posição de Castro (2005, p. 254), para quem é preciso desenvolver uma cultura de avaliação - e uma competência para entender seus resultados para que seu uso não seja baseado apenas em palpites. Além disso, deve haver espaço para que a análise dos resultados de um determinado sistema considere os dados de outros sistemas externos (como, por exemplo, o $\mathrm{Saeb}$ ), bem como das pesquisas acadêmicas relacionadas à qualidade de ensino, para que as conclusões resultantes possam vir a contribuir, de maneira eficaz, para a tomada de decisões.

b) A dificuldade de comunicação com os diversos públicos de um programa de avaliação. As comunidades escolares e os demais públicos têm um perfil muito heterogêneo: é imprescindível garantir uma comunicação eficaz, o que implica a busca constante por uma linguagem que consiga atingir a todos. Essa dificuldade está especialmente atrelada à demanda por envolvimento dos pais e da comunidade no monitoramento da escola, considerado, em muitas propostas de reforma, essencial para garantir a melhoria do serviço prestado.

c) A competição por recursos orçamentários que, muitas vezes, faz com que as estratégias de avaliação sejam prejudicadas, com implicações para a confiabilidade dos resultados, ainda que os recursos tenham sido assegurados na momento da formulação.

Como pode ser visto, a avaliação, embora tenha ocupado um lugar de destaque nas políticas públicas nos últimos anos, defronta-se com uma série de obstáculos. A falta de sustentação das políticas ao longo do tempo ${ }^{8}$, com mudanças, às vezes freqüentes, de objetivos e de procedimentos, e a falta de recursos comprometem a utilização dos dados em séries históricas e a formação de uma massa crítica capacitada, impedindo a consolidação de uma cultura de avaliação.

No que se refere ao uso dos resultados, técnico ou político, as dificuldades são encontradas tanto no nível escola quanto nos sistemas (Heyneman, 2005; Castro, 2005). Uma hipótese para a falta de ou inadequação do uso pode argumentar quanto à não-capacitação dos atores para entender e se relacionar com os aspectos técnicos dos sofisticados

8 Como exemplo, é interessante verificar as mudanças propostas ao modelo Saeb, criado para ser uma fonte de informação para os sistemas e que, a partir da portaria 931, de 21 de março de 2005, é transformado em Sistema de Avaliação da Educação Básica, composto pela ANEB e pela ANRESC, a última propondo-se a oferecer resultados individualizados por escola; as dificuldades encontradas pelo SAEPE, em Pernambuco, e a descontinuidade das políticas de avaliação externa na Bahia. Para uma visão sobre tais políticas, implementadas durante o período pesquisado, consultar Bonamino, Franco e Bessa (2004). 
programas de avaliação. Outra hipótese relaciona essa questão à falta de participação dos atores nos processos decisórios que levaram ao delineamento da avaliação, sem que haja, portanto, apropriação posterior de seus resultados.

Mesmo com problemas, as avaliações proliferaram. Em muitos casos, a implementação desses programas se deu mediante a parceria Estado x Universidades ou pela contratação de agências especializadas. Em outros, algumas etapas de implementação ficaram sob responsabilidade de técnicos especializados e as demais sob o comando da escola. Em todos os casos, a mudança na qualidade da educação dependeu e depende da unidade escolar. Por essa razão, o próximo bloco descortina as questões da escola de hoje que afetam a forma como ela recebe as políticas de avaliação.

\subsection{A Escola e a Avaliação em Larga Escala}

A possibilidade de sucesso das políticas de avaliação talvez esteja no entendimento de que, independente de seus objetivos ou de quão agregados ou individualizados sejam seus resultados, uma mudança que implique melhoria da qualidade de ensino só se realiza a partir de uma mudança na sala de aula (Sousa, 1997). A escola não é apenas fonte de dados, é o local onde a mudança acontece. Diante desse entendimento, é importante questionar: que escola é essa na qual a política de avaliação se materializa e para a qual é formulada?

Essa escola, principalmente a pública, está em crise de identidade. A "velha escola" é descrita por Luckesi (2000), ao tratar do conservadorismo nas instituições de ensino e do autoritarismo expresso nas formas de avaliação utilizadas. Para esse autor, além de dispor de uma cultura altamente tradicional (característica de uma entidade que ensina para gerações), as organizações de ensino tendem a apresentar: a) morosidade no fluxo de informações, muitas vezes induzida por seus próprios membros, que não estão motivados a obtê-las; b) crença subliminar na competição individualizada; c) falta de competência técnica que garanta ao membro da instituição sua autonomia; d) falta de entendimento da necessidade de participação no processo de elaboração do projeto políticopedagógico da organização; e) falta de diálogo franco e de cultura de feedback; f) falta de capacitação contínua em aspectos estratégicos; e g) substituição dessa capacitação por treinamentos relacionados a atividades pedagógicas.

Hoje, a essa velha escola estão sendo atribuídas as mazelas da educação. Uma série de demandas é colocada sobre ela, provocando conflitos que afetam sua identidade. Da escola foram e são esperados, além 
de uma educação de qualidade que forme o cidadão e prepare o país para competir no mundo globalizado, serviços de alimentação (merenda escolar), assistência social (acompanhamento dos alunos em suas casas e busca dos evadidos), saúde (com oferta, dentro da área escolar, de atendimento médico-odontológico), dentre outros (Cavaliere, 2002). Principalmente cabe à escola assumir o papel que um dia foi da família: para muitos alunos, seus muros delimitam o único local de proteção e organização que eles conhecem (ainda que muitas das propostas de reforma vejam os pais dos alunos como parceiros, em um aparente contrasenso). Aos professores e dirigentes, além de conhecimento, foram também cobrados que fornecessem limites, atenção e amor (!). De maneira mais geral, como elo final na cadeia política, espera-se que a nova escola:

a) realize uma gestão democrática, com participação de representantes dos seus diversos segmentos em um colegiado (Oliveira, 2002);

b) esteja comprometida com uma racionalidade de aumento de eficiência, observando inclusive formas de gestão do setor privado (Nogueira, 2002);

c) elabore um projeto político-pedagógico e um regimento próprios, mas obedientes aos sistemas públicos, pois as questões de currículo, avaliação externa, organização didática e uso de recursos (as rubricas são pré-determinadas) são definidas de maneira centralizada (Gentili, 1996);

d) comprometa esse projeto político-pedagógico com a "inclusão social e a emancipação do ser humano" (Bahia, 2000);

e) deflagre campanhas de interesse público, formando parcerias e organizando sua execução, tudo dentro da visão posta no projeto político-pedagógico e de maneira a enriquecer a aprendizagem (Algarte, 2001);

f) passe a ser um ambiente facilitador das aprendizagens e não mais um lugar de ensino, com ênfase no "aprender a aprender" (Sander, 2002, p. 63). A transmissão de conhecimento deixa de ser perseguida e os esforços são concentrados na utilização dos conhecimentos adquiridos, em um processo de aprendizagem ativa;

g) desencadeie os processos de mudanças da sociedade (Algarte, 2001);

h) insira seu alunado no mercado de trabalho, preparando-o para a vida (Nogueira, 2002);

i) consiga tratar seus alunos de forma eqüitativa, de modo a promover, por igual, as chances de sucesso na vida, 
independentemente dos diferentes perfis do alunado que esteja recebendo.

A lista, brevemente iniciada acima, é infindável quando se buscam as demandas para a escola dos dias de hoje. Muitos dos críticos dos processos de reforma reclamam do excesso de exigências em um contexto de formação docente inadequada, baixos salários e condições adversas de trabalho. Se, por um lado, não existe um único modelo de ensino, por outro, experimentações em educação podem ser dolorosas, especialmente pelo peso social caso um erro aconteça, fazendo com que a unidade escolar se sinta mais atingida pela ameaça que pelo desafio ao se defrontar com uma proposta de mudança. Assim, no máximo, a organização de ensino busca adaptar-se às exigências externas, sem, contudo, ter opções imediatas de transformação, especialmente no caso da escola pública.

Essa adaptação "superficial" pode ocorrer também em relação às políticas de avaliação. Logo de início, a escola pode perceber certa incoerência entre essas políticas - associadas a um levantamento quantitativo de competências e habilidades em determinadas disciplinas isoladas - e os posicionamentos do governo federal na LDB/96 e nas diretrizes curriculares nacionais, que dão ênfase à avaliação qualitativa. Ainda assim, da escola é esperado que obtenha resultados, no mínimo, proficientes, o que, para muitas, significa reduzir seus objetivos àqueles especificados nas matrizes de referência dessas políticas. De acordo com Libório e Costa (2004, p. 701), a legitimidade da escola pública depende de sua conformidade com o meio institucional e, por essa razão, os processos de avaliação são aceitos e respeitados, ainda que como rituais, porém não são integrados à vida escolar.

Três outros aspectos relativos à escola pública de hoje merecem ainda ser ressaltados, diante de sua importância para atingir os objetivos das políticas de avaliação em larga escala. São eles: a heterogeneidade da unidade escolar, a expectativa de participação dos pais e comunidade na busca pela melhoria da qualidade do ensino e a resistência possível da comunidade escolar aos processos de autonomia e descentralização.

Qualquer estudo de implementação de políticas de avaliação que use a escola como fonte de dados precisa levar em consideração a diversidade intra e inter escolar. Embora certos aspectos comuns sejam identificáveis em muitas unidades, uma vez que o sistema educacional exerce sobre elas grande pressão expressa em normas, leis e auditorias (a escola é institucionalizada), cada uma reage a essa pressão individualmente. Internamente, essa escola, como qualquer organização, não se comporta como um bloco coeso (Perez Gomes, citado por Oliveira, 2003 , p. 300). Políticas que precisem de padronização dos processos sob 
responsabilidade de um grande número de implementadores, como as de avaliação em larga escala, precisam considerar essa diversidade e, a partir dela, propor as possibilidades de monitoramento. Nesse momento, instaura-se um conflito entre necessidade $x$ custos de controle que, em várias ocasiões, chegam a inviabilizar uma política. Uma das respostas a esse problema sugere a utilização da comunidade em volta da escola como agente de monitoramento, de referência e de pressão (Barroso, 2002).

Esse envolvimento precisa ser considerado, porque a participação da comunidade está muito longe de ser a esperada. Isso se dá por dois motivos: os pais estão acostumados com o discurso que responsabiliza seus filhos pelo insucesso escolar, o que os deixa de mãos atadas para discutir processos e metodologias com a escola, além de que, muitas vezes, não têm competência para tal; o segundo motivo diz respeito à não voluntariedade dos pais de alunos de escolas públicas. Como posto por Lipsky (1980), esses clientes-usuários não podem escolher os serviços aos quais estão se submetendo. A escolha poderia ocorrer no sentido de tirar seus filhos da rede pública e colocá-los na rede particular, mas não há recursos para isso. Da mesma maneira, tirar seus filhos das escolas mais próximas às suas residências e matriculá-los em locais mais distantes implica custo de transporte, muitas vezes uma barreira intransponível. Assim, há certo determinismo geográfico ainda que a rede pública permita matrículas não atreladas a endereço residencial. A relação desses pais com a escola de seus filhos é de co-dependência e eles são pressionados a agir dentro dos limites impostos por essa organização (Lipsky, 1980, p. xiv). Por essa razão, é difícil transformar pais e responsáveis por alunos em co-implementadores ou ainda em elementos de controle da política que está sendo implementada.

O terceiro aspecto a considerar, no delineamento de políticas de avaliação em larga escala (no modelo estabelecido pelo Saeb, no Brasil, por exemplo), é que elas representam a contrapartida para o processo de descentralização e autonomia, servindo, em alguns Estados, como ferramenta para responsabilização da escola perante a sociedade. Entretanto, muitas unidades escolares consideram a descentralização como um fardo, especialmente em situações nas quais elas não tiveram novas prerrogativas (orçamento, questões de pessoal) (Corrales, 2000, p. 42). A resistência aos processos de implementação das políticas de reforma, nesse caso, é oriunda do acréscimo de demandas para a agência implementadora, sem um favorecimento de condições de trabalho que traduzam autonomia.

É nesse cenário, que fortalece a avaliação externa por um lado e que deixa mais sobrecarregada a escola por outro, que se implementa a Avaliação da Aprendizagem. A seção a seguir descreve essa política como 
originalmente formulada, para que, nas seções posteriores, sejam apresentadas a metodologia empregada na pesquisa e os resultados, atrelados ao modelo de análise oriundo da proposta de Lipsky (1980).

\section{A POlítica SOB ESTUdo: O MODElO DA AVAliAÇÃO DA APRENDIZAGEM}

A política de Avaliação da Aprendizagem foi colocada em ação em 2001. Discrepante em relação a outras experiências de avaliação no Brasil, ela teve um caráter menos regulatório e mais social, uma vez que seu objetivo final veio a ser instrumentalizar as unidades escolares com ferramentas diagnósticas a cada 200 horas letivas. Essa abordagem lhes permitiria flagrar problemas na aquisição de competências e habilidades pelos seus alunos, durante o ano letivo, a tempo de serem colocadas em prática ações de remediação que, em último caso, resultariam em uma menor taxa de reprovação e no oferecimento de um melhor serviço educacional. Ao mesmo tempo em que apresentava instrumentos criados a partir de uma referência comum para todo o Estado, a Avaliação da Aprendizagem convidou os professores, coordenadores pedagógicos e diretores a analisarem seus resultados a partir de suas próprias realidades para propor soluções passíveis de implementação imediata.

De 2001 a 2004, três vezes ao ano, testes de Língua Portuguesa e Matemática foram administrados para alunos de $1^{\mathrm{a}}$ a $4^{\mathrm{a}}$ série. Com isso, as aplicações envolveram também os alunos iniciantes na expectativa de, ao corrigir os problemas logo no início, impactar positivamente o fluxo educacional (Universidade..., 2004).

A implementação da Avaliação da Aprendizagem pela escola pode ser dividida em três diferentes fases: 1) o planejamento, 2) a aplicação e correção dos testes e 3) a discussão dos resultados, com propostas de ação corretiva. Houve três tipos de procedimentos e ações nessa política: o normalizado, o sugerido e o aberto9 ${ }^{9}$ A orientação das escolas sobre a

9 Essa terminologia foi criada a partir da proposta de Lima (2002), sobre modelos decretados, interpretados e criados. Para fins deste estudo, foram considerados o modelo normalizado (pois a Avaliação da Aprendizagem não foi implementada através de decretos ou portarias), o modelo sugerido e o modelo aberto. O modelo normalizado refere-se às orientações determinadas pelos formuladores da política, cuja expectativa é de que sejam fielmente cumpridas; o sugerido diz respeito àqueles padrões a serem implementados que contam com uma margem de escolha do implementador; por fim, o modelo aberto engloba todas as etapas da política que não foram previstas pelo formulador, ou que, desde seu desenho original, contam com a poder de decisão local para que sejam atingidos os seus objetivos gerais. 
Avaliação da Aprendizagem foi feita por meio de manuais, matrizes e ofícios, além das provas e visitas de sensibilização. Em geral, os procedimentos normalizados estiveram relacionados à aplicação e correção das provas. Os procedimentos sugeridos foram associados às questões para as quais se esperou que a escola se auto-organizasse e adotasse os caminhos que melhor a atendessem. Os aspectos deixados em aberto envolveram a interação da avaliação externa com o projeto político pedagógico de cada unidade e o uso estratégico de seus resultados. O acompanhamento de toda a ação nas escolas foi feito por meio do Relatório do Diretor ${ }^{10}$. Um estudo em uma amostra controlada foi conduzido para permitir ao Estado e municípios um diagnóstico geral das escolas envolvidas pelo sistema de avaliação, de maneira a informar as decisões sobre novas políticas. À exceção dessa amostra, a implementação da Avaliação da Aprendizagem dependeu fundamentalmente da equipe escolar para sua aceitação, entendimento e obediência à padronização.

A Figura 1 sintetiza as etapas de planejamento, aplicação e uso dos resultados, registrando dois movimentos de feedback possíveis dentro da escola: aquele que leva o uso dos resultados a uma reflexão sobre o planejamento do curso, de caráter mais estratégico, e aquele que trata de questões mais imediatas, de operacionalização das aplicações de prova. Em seguida, essas etapas são detalhadas.

10 Formulário encaminhado às escolas a cada aplicação de provas, por meio do qual seus dirigentes comunicaram, à equipe coordenadora, ocorrências no planejamento, aplicação e correção das provas, bem como proposições feitas a partir da correção e diagnóstico em sua unidade escolar. Em nenhum momento foi pedido que as escolas registrassem os resultados obtidos. 
Figura 1 - Etapas de implementação da Avaliação da Aprendizagem, nos seus procedimentos normalizados, sugeridos e abertos

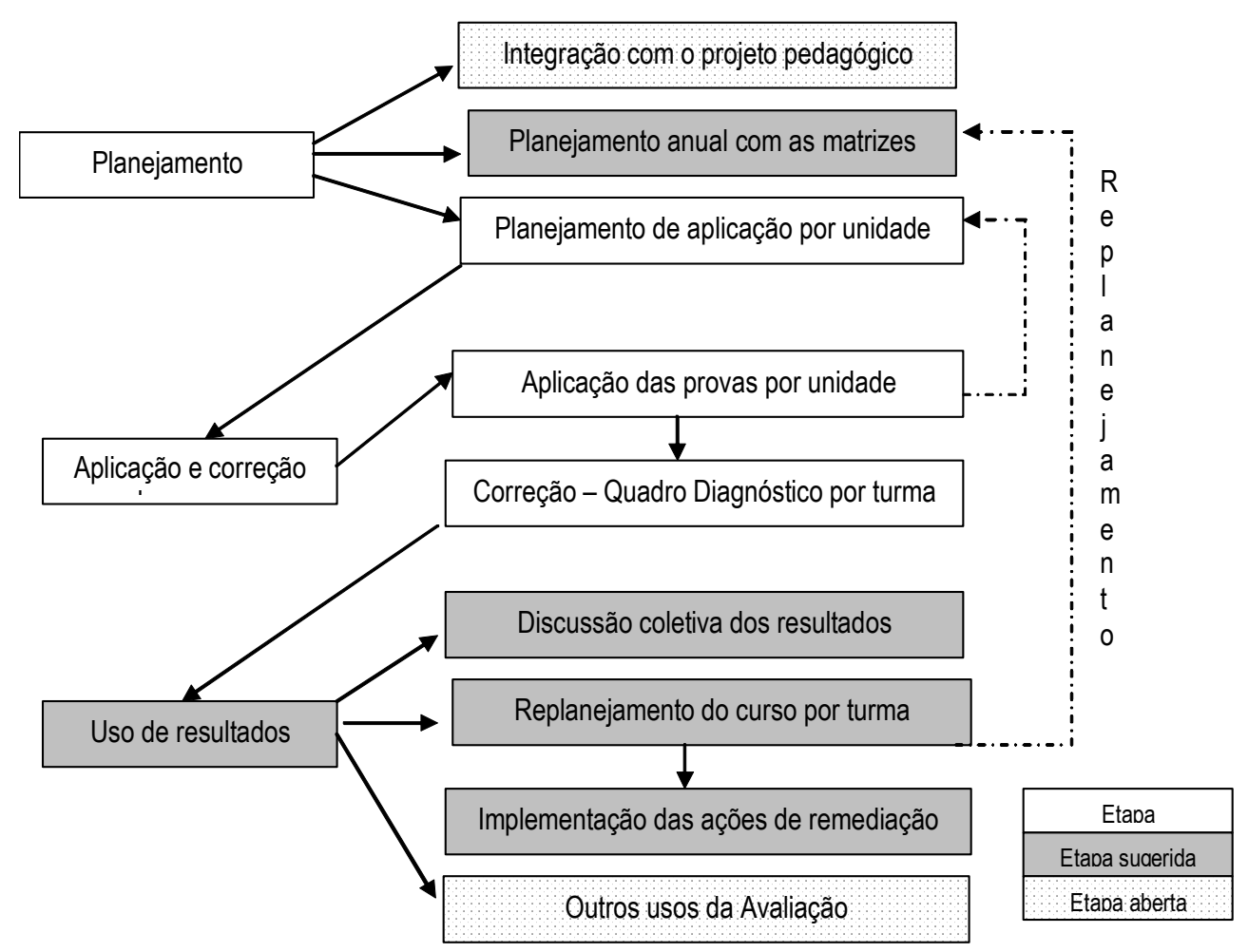

\subsection{Etapa de Planejamento}

Em relação à integração da avaliação externa ao projeto políticopedagógico em cada unidade escolar, foi apenas colocado, nas matrizes e textos da avaliação, que a Avaliação Externa não deveria substituir, sob qualquer hipótese, a avaliação interna, realizada pela escola de acordo com seu posicionamento pedagógico. A maneira de integrar as duas avaliações deveria ser decidida pela escola. 
Quanto ao planejamento anual, no início de cada ano e em paralelo à divulgação das matrizes de referênciai1, foi sugerido às escolas que discutissem esses documentos durante a semana pedagógica. Dessa maneira, os objetivos mínimos da avaliação externa poderiam ser inseridos no plano de curso da escola, com o cuidado de não serem confundidos com um currículo estadual. Cada escola desenvolveu essa etapa de acordo com seu entendimento das matrizes e da utilidade desse material para o seu planejamento.

O planejamento das aplicações foi normalizado. Os diretores deveriam planejar a aplicação das provas de acordo com os procedimentos postos nos manuais do diretor, e as provas deveriam ser aplicadas logo após o término da unidade letiva na escola. Uma reunião para discussão dos resultados deveria também ser planejada. A cada unidade, um novo manual foi impresso e encaminhado juntamente com as provas e o Relatório do Diretor.

\subsection{Etapa de Aplicação e Correção}

Os próprios professores aplicaram e corrigiram as provas. Os procedimentos e a padronização foram encaminhados às escolas em manuais e materiais explicativos, lembrando-as de que quebras no padrão de aplicação dos testes e da sua correção teriam implicações sérias nas informações resultantes, podendo comprometer qualquer análise que delas viesse a ser feita. Para aplicação, os professores deveriam ler o roteiro que constava nos manuais.

As provas foram elaboradas de maneira a fornecer um resultado por turma e não por indivíduo. A correção, inclusive das provas de produção textual (com questões abertas), foi também padronizada. Os resultados deveriam ser reunidos em um quadro-diagnóstico, que permitiria o resultado da turma por domínio de conteúdo. Para cada prova, o projeto informou o porcentual de acertos correspondente à proficiência mínima, identificado unidade a unidade, por meio de procedimentos de definição de padrão modificado por Angoff.

11 Uma das primeiras ações do Projeto de Avaliação Externa foi a definição da relação de competências e habilidades a serem mensuradas por meio de provas padronizadas, chamada Matriz de Referência da Avaliação da Aprendizagem. Um esforço de comunicação foi feito pela equipe do projeto na divulgação desses documentos, publicados em formato de livro, no qual cada uma das competências e habilidades a serem avaliadas foi exemplificada com questões em formato semelhante ao da prova, de modo a facilitar o seu entendimento pelos professores. Todo o material está disponível para consulta na página http://www.aval.ufba.br. 


\subsection{Etapa de Uso dos Resultados}

Atendendo aos princípios de autonomia e ação local postos pelo programa estadual, a etapa de utilização dos resultados dependeu fundamentalmente de cada unidade escolar. A expectativa dos formuladores da Avaliação da Aprendizagem era de que as secretarias de educação apoiassem as ações planejadas por suas escolas com base na análise dos resultados de cada aplicação.

Orientações sobre como analisar os resultados foram apresentadas para as escolas em cartas-ofício, manuais e em visitas de consultores temporários contratados pelo Projeto de Avaliação Externa. Em 2003, um guia-diagnóstico foi introduzido nos manuais de aplicação, para facilitar a análise dos resultados, mas não foi encaminhado um roteiro sobre "o que fazer" a partir dela. As sugestões do projeto para as escolas, nessa etapa, foram:

1 - Promover uma discussão coletiva sobre os resultados, pelo menos entre os professores de cada uma das séries avaliadas. Para essa reunião, os professores já deveriam ter corrigido as provas, preenchido o quadro-diagnóstico e feito uma reflexão a partir do guia-diagnóstico. O produto dessa reunião seria um replanejamento de curso e aulas, com base nas experiências utilizadas nas turmas com melhor desempenho, e, talvez, um indicativo de necessidade de capacitação dos docentes.

2 - Implementar ações de remediação, quando identificadas defasagens nas turmas em relação às matrizes de referência. $O$ projeto elaborou, como reforço à remediação, vídeos didáticos voltados para os alunos. Esses vídeos tratavam, em várias abordagens diferentes, dos conteúdos nos quais os alunos apresentaram maiores dificuldades, identificadas na correção de provas aplicadas a amostras controladas. Foram também encaminhados às escolas livretos escritos por pedagogos especializados, como complemento às atividades desenvolvidas nos vídeos.

O contexto e o delineamento do Projeto de Avaliação Externa e, em especial, da Avaliação da Aprendizagem, mostram que à escola pública foi pedido um comportamento autônomo, sem que houvesse realmente uma concessão de autonomia. A discussão desse contexto e da articulação da avaliação externa com as demais políticas estaduais e dos municípios parceiros não fazem parte do escopo deste artigo, embora tenham sido consideradas na pesquisa sobre implementação. A seção a seguir trata brevemente da metodologia utilizada para a investigação da política de Avaliação da Aprendizagem para que, no bloco seguinte, possam ser apresentados seus resultados. 


\section{A INVESTIGAÇÃO}

O estudo aqui descrito teve como objeto a implementação da política de Avaliação da Aprendizagem, a partir de relatos de sua concretização em 163 escolas públicas urbanas situadas em 11 municípios do Estado da Bahia, no período 2002-2003. Para tanto, adaptou a abordagem proposta por Lipsky (1980) para estudo de implementação de políticas públicas, ao contrastar as orientações oficiais encaminhadas às escolas (política normalizada) com os padrões de prática por elas relatados (política relatada), analisando-os à luz de suas condições de trabalho. Essas categorias serão melhor detalhadas na próxima seção, quando da apresentação dos resultados. Os dados usados foram obtidos com base em documentos existentes, relacionados à política definida, e de 654 Relatórios do Diretor.

Para buscar as características finais da Avaliação da Aprendizagem, as etapas desse trabalho incluíram a análise da política normalizada, a consolidação dos relatos sobre práticas de implementação (padrões de prática), sua associação com a percepção das condições de trabalho (foram consideradas apenas as associações medianas e fortes - Gamma $\Upsilon>0,50$ ) e, finalmente, o contraste entre a política normalizada e a política relatada. Foram, portanto, considerados os níveis de formulação, para descrição da política, e de implementação, a partir de relatos. A busca de associação entre as práticas e as condições de trabalho foi conduzida na tentativa de confirmação da proposta de Lipsky, de que essas estratégias são uma resposta do burocrata e de suas agências às condições adversas de trabalho. A Figura 2 ilustra a lógica utilizada neste estudo. 
Figura 2 - Representação do desenho da pesquisa sobre a implementação da política de Avaliação da Aprendizagem

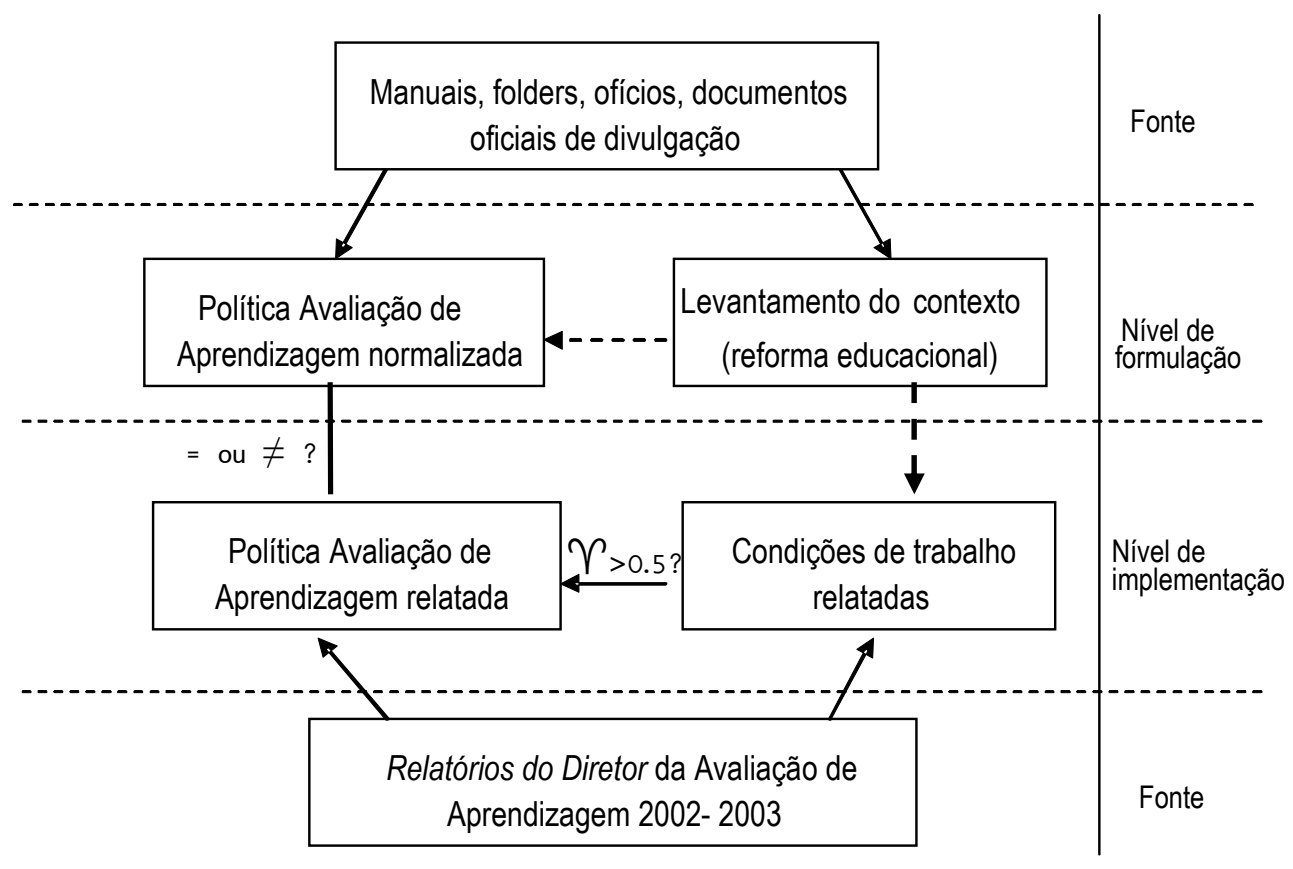

Para participar do estudo, foram envolvidas todas as escolas urbanas, de onze municípios que tivessem enviado, durante as seis aplicações de 2002 e 2003, pelo menos 1 Relatório do Diretor ao Projeto de Avaliação Externa. Esses onze municípios foram escolhidos a partir de três características: 1) regularidade no envio dos Relatórios do Diretor por, pelo menos, $75 \%$ das escolas envolvidas na Avaliação da Aprendizagem, para garantir a análise do discurso das escolas ao longo das seis aplicações; 2) diversificação geográfica, de modo que várias diretorias regionais da SEC estivessem presentes na amostra e, portanto, características regionais pudessem aflorar da leitura dos relatórios, caso houvesse; e 3) diversificação dos municípios por tamanho para que dinâmicas entre escolas pudessem ser observadas da leitura dos relatórios. O número de escolas urbanas foi o elemento utilizado para caracterizar o tamanho dos municípios ${ }^{12}$. Por ser intencional, essa amostra não pode ser considerada representativa do grupo de implementadores, embora a quantidade de documentos analisados permita uma visão ampla sobre as questões de sua

12 Os dois maiores municípios - Salvador e Feira de Santana - não foram considerados, por apresentarem características muito diferentes dos demais. 
implementação. A próxima seção detalha as categorias de pesquisa e apresenta seus principais resultados.

\section{ANÁliSE DE IMPLEMENTAÇÃO DA POLÍTICA DE AVALIAÇÃO DA APRENDIZAGEM}

Reconhecendo a importância da escola para as políticas de avaliação, especialmente como usuária dos resultados, e, no caso particular da experiência em estudo, como responsável pelas principais etapas de implementação, optou-se por uma perspectiva bottom-up para análise da Avaliação da Aprendizagem. De acordo com Souza (2002), a importância desse tipo de análise cresce a partir da publicação de Burocracia de linha de frente: dilemas do indivíduo no serviço público, de Lipsky (1980).

Nessa obra, Lipsky delineia o papel do burocrata de linha de frente $^{13}$ e discute o impacto que suas ações e decisões têm nos "clientesusuários" com os quais interage e, dado o seu grande grau de discricionariedade, no processo de implementação de qualquer política. $\mathrm{O}$ autor argumenta que as rotinas utilizadas pelos agentes públicos e as estratégias de enfrentamento ${ }^{14}$ por eles criadas para lidar com as pressões decorrentes das condições de trabalho acabam por moldar a política pública a qual estão responsáveis por implementar. Assim como Lipsky, Dye (1995, p. 316) acredita que razões profissionais e pessoais do servidor público estão juntas para fazê-lo tender para a expansão de poderes e funções de sua agência, aumentando assim seus orçamentos e poderes, especialmente aqueles discricionários. Com relação à política educacional, Walker (2004, p. 340) argumenta que a comunidade escolar interpreta, responde e implementa políticas através de modos que estejam em acordo com suas experiências. Conseqüentemente, nem sempre a política concretizada é aquela originalmente formulada. Assim, os burocratas de linha de frente passam de implementadores para reais formuladores de política pública.

Para fins deste estudo, foram observadas as duas dimensões postas por Lipsky: 1) condições de trabalho e 2) padrões de prática utilizados,

13 Tradução para street-level bureaucrat, definido como o funcionário público que interage diretamente com os cidadãos durante o desenvolvimento de suas funções. Estão incluídos nessa categoria agentes policiais, professores, assistentes sociais, juízes, advogados ou qualquer outro que atue representando o governo. As unidades - como hospitais e escolas - que empregam um número grande de burocratas de linha são denominadas burocracias de linha ou agências burocráticas de linha.

14 Tradução para coping strategies. 
como expressão das estratégias de enfrentamento, a partir das quais foram relacionadas as categorias e seus indicadores. Como condições de trabalho, foram consideradas as categorias Alienação, Inadequação de Recursos e Percepção de Conflito. Como práticas, foram escolhidas Racionamento, Simplificação e Diferenciação de Clientes. A esse grupo de categorias da dimensão Padrões de Prática foi associada a categoria Conformação, que trata da institucionalização do discurso das agências implementadoras, como forma de sobrevivência, como explicado por Meyer e Rowan (1991), citados por Libório e Costa (2004, p. 698). Para esses autores, a legitimidade institucional depende não da eficácia dos procedimentos, mas da conformidade com os meios institucionais e as técnicas, as politicas e programas que se institucionalizam nas organizações funcionam como "mitos racionais", adoptados cerimonialmente.

A Figura 3 ilustra as categorias utilizadas nesta pesquisa ${ }^{15}$. Em seguida, é apresentado o perfil das escolas pesquisadas, com ênfase na estabilidade do cargo de diretor da escola e na freqüência de envio dos Relatórios do Diretor ao Projeto de Avaliação Externa, duas características que poderiam impactar a implementação da avaliação.

Figura 3 - Representação das categorias de análise do quadro teórico de referência

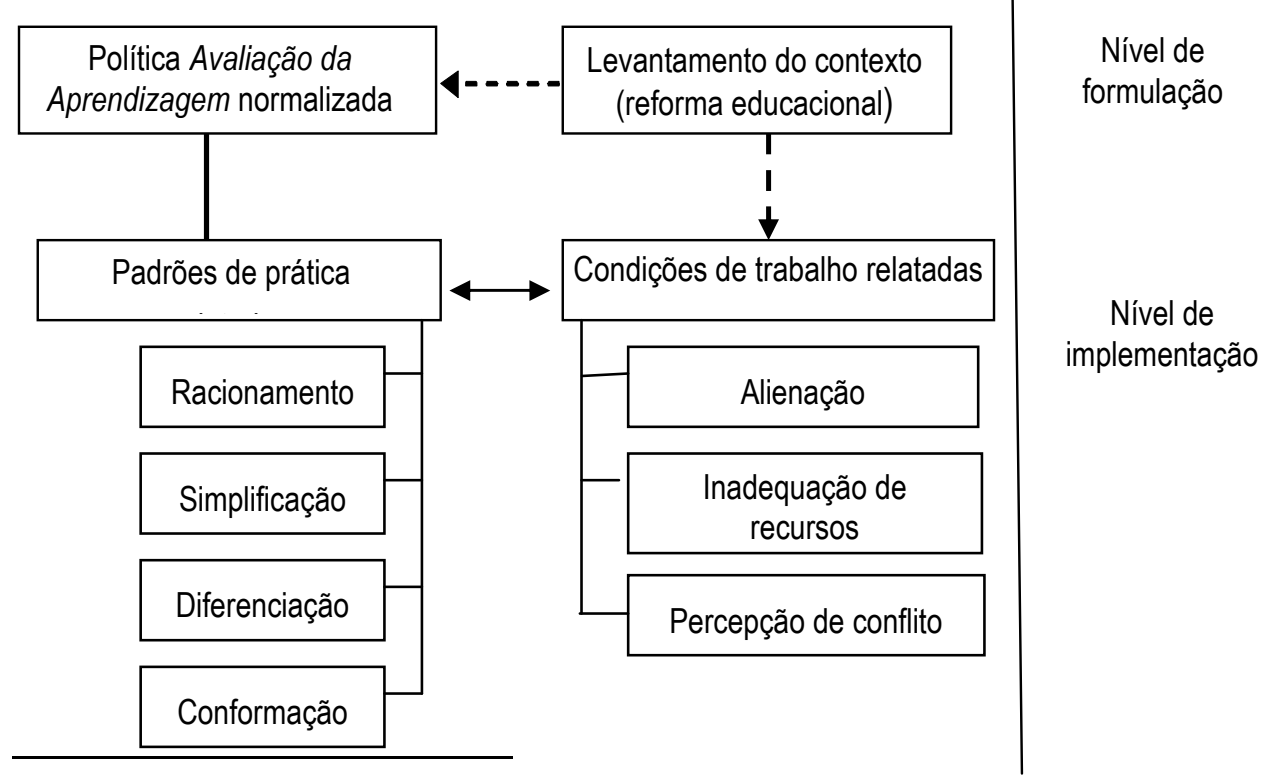

15 É importante ressaltar que o quadro de referência foi criado para possibilitar a análise dos desvios de implementação no desenho da Avaliação da Aprendizagem, e não o contrário (o impacto dessa política nas práticas da escola). 


\subsection{Perfil das Escolas Implementadoras}

As escolas que contribuíram para esse estudo foram cadastradas, no Censo Escolar de 2001, 2002 e 2003, como escolas públicas situadas na zona urbana. Quanto a seus tamanhos, apenas uma escola tinha um número superior a 1.001 alunos matriculados nas quatro primeiras séries do Ensino Fundamental, enquanto 125 delas tinham um número inferior a 500 (12 das quais com menos de 50 matrículas ao todo). Da amostra estudada, 20\% pertenciam à rede estadual e $80 \%$ à rede municipal.

Foram levantadas, para o período de 2002-2003, as mudanças na direção dessas escolas, em cinco diferentes categorias: 1) Não houve mudança de diretor; 2) Houve mudança de diretor em 2002; 3) Houve mudança de diretor entre 2002 e 2003; 4) Houve mudança de diretor em 2003; e 5) Não é possível resgatar essa informação. O objetivo foi observar se houve variação nas práticas e na percepção das condições de trabalho, levantadas através dos relatórios, decorrente de mudança de dirigente. Em especial, foi observado se houve variação na freqüência de envio de Relatórios do Diretor. Foi grande o porcentual de escolas nas quais não foi possível obter a informação sobre troca de diretores (33\% para a rede municipal e $38 \%$ na rede estadual). Das que relataram, em $68 \%$ das escolas municipais e em $85 \%$ das escolas estaduais não houve troca de diretores, configurando um certo nível de estabilidade. Apesar da expectativa de que trocas de diretores teriam alguma associação com a percepção das condições de trabalho ou com a freqüência de envio dos Relatórios do Diretor, na amostra estudada, essa associação foi fraca e não significativa, a um nível de 0,05.

Ainda que não associada à mudança na direção da escola, a freqüência observada no envio dos relatórios seguiu um padrão que já havia sido identificado, na rede estadual, na avaliação do curso de aperfeiçoamento de professores promovida pelo Instituto Nacional de Estudos e Pesquisas Educacionais Anísio Teixeira - Inep (Brasil, 1998): as escolas tendem a responder mais favoravelmente às demandas externas na primeira unidade e a fazê-lo em menor freqüência no segundo semestre. Para as 163 escolas pesquisadas, o maior retorno, nas duas redes, ocorreu na primeira unidade de 2002 . O menor retorno da rede estadual aconteceu na terceira unidade de 2003 e da rede municipal na terceira unidade de 2002. É interessante perceber, contudo, que o ano de 2003 teve menor retorno, em geral, que o ano de 2002.

Esse dado deverá ser melhor investigado no futuro, mas uma das hipóteses para explicá-lo pode estar ligada à percepção dos professores quanto ao uso da Avaliação Externa e o resultado prático que ela trouxe (ou 
não) para a escola, em contraste com o aumento da carga de trabalho que provocou. É possível que, em um contexto onde a autonomia não se concretizou, com o passar do tempo a escola tenha optado por deixar de lado os mecanismos criados como contrapartida para essa autonomia (como a avaliação). Ao buscar associar a participação das escolas (representadas pelo número de relatórios enviados por escola em 2002 e 2003) com suas percepções sobre condições de trabalho, não houve nenhum resultado considerado mediano ou forte (todas as associações propostas tiveram $\gamma$ inferior a 0,48 ).

Após esse breve perfil das escolas pesquisadas, a subseção a seguir traz uma síntese da percepção de diretores e professores, relatada nos Relatórios do Diretor, quanto a suas condições de trabalho.

\subsection{Percepção das Condições de Trabalho}

Três categorias compõem essa dimensão: Inadequação de Recursos, Percepção de Conflitos e Alienação. No total, doze indicadores foram levantados. Para apresentação dos resultados, optou-se por agrupar os indicadores por categoria, a partir do olhar de Lipsky (1980).

\section{Inadequação de recursos}

Para Lipsky (1980), um dos grandes problemas do serviço público é a necessidade de cumprir metas, muitas vezes arrojadas e ambíguas, com poucos recursos ou com recursos inadequados. Essa inadequação seria uma das condições de trabalho mais estressantes para o burocrata de linha de frente e um dos fatores para o desenvolvimento de estratégias de enfrentamento que resultariam, em última análise, na mudança das feições da política pública cuja implementação está sob responsabilidade de sua agência. Esse quadro não deveria ser diferente para as escolas públicas.

A Tabela 1 mostra o porcentual de escolas que comentaram, pelo menos uma vez ao longo de seis unidades, sobre inadequação de recursos, de maneira geral, e/ou falta de provas e materiais específicos da Avaliação Externa. Nessa categoria, foram considerados seis diferentes indicadores. 
Tabela 1 - Porcentual de escolas, por rede, que relataram condições de trabalho relacionadas à categoria Inadequação de Recursos, pelo menos uma vez nas seis aplicações estudadas

\begin{tabular}{|l|c|c|}
\hline \multicolumn{1}{|c|}{ Inadequação de Recursos } & $\begin{array}{c}\text { Rede } \\
\text { Estadual }\end{array}$ & $\begin{array}{c}\text { Rede } \\
\text { Municipal }\end{array}$ \\
\hline $\begin{array}{l}\text { Contribuição da Avaliação da Aprendizagem para a carga de } \\
\text { trabalho considerada excessiva }\end{array}$ & 9,38 & 11,45 \\
\hline $\begin{array}{l}\text { Falta de material específico para operacionalização da } \\
\text { Avaliação da Aprendizagem }\end{array}$ & 53,13 & 59,54 \\
\hline $\begin{array}{l}\text { Falta de material e/ou pessoal de apoio pedagógico para } \\
\text { melhorar a qualidade da educação na escola }\end{array}$ & 18,75 & 7,63 \\
\hline $\begin{array}{l}\text { Falta de infra-estrutura para cumprir os procedimentos da } \\
\text { Avaliação da Aprendizagem }\end{array}$ & 15,63 & 11,45 \\
\hline $\begin{array}{l}\text { Despreparo dos docentes para lidar com a Avaliação da } \\
\text { Aprendizagem }\end{array}$ & 18,75 & 9,92 \\
\hline $\begin{array}{l}\text { Despreparo dos docentes para lidar com as disciplinas sob } \\
\text { avaliação }\end{array}$ & 9,36 & 6,11 \\
\hline
\end{tabular}

O primeiro dos seis indicadores merece um detalhamento visto que agrupou informações sobre uma das maiores preocupações da equipe técnica do Projeto de Avaliação Externa: a carga que a Avaliação da Aprendizagem acrescentaria ao trabalho das escolas (para o grupo de docentes e a jornada de trabalho já considerados insuficientes), ampliada, em 2003, com a inserção de um guia-diagnóstico nos manuais de aplicação ${ }^{16}$. Todas as atividades de aplicação, correção e análise de resultados deveriam ser realizadas em um período de duas semanas, no máximo, para que os professores tivessem tempo de implementar as ações do seu replanejamento durante a unidade letiva em curso. Observou-se que um porcentual relativamente pequeno de escolas registrou algum comentário sobre esse aumento de trabalho $(9,38 \%$ estaduais e 11,45\% municipais), mas outras questões foram levantadas, como pode ser visto nos trechos transcritos abaixo:

Cabe ao projeto corrigir as provas; elas tomam tempo e atenção dos professores.

Uma das críticas do professor refere-se ao guia-diagnóstico, cheio de questionamentos, que exige um certo tempo para responder.

16 O guia-diagnóstico foi constituído por uma série de perguntas e tinha por objetivo ajudar o professor na análise dos resultados e reflexão sobre seus planos de trabalho e, dessa forma, contribuir para o fluxo de discussões durante as reuniões organizadas pela direção da escola, após a correção dos testes da Avaliação da Aprendizagem. 
Os professores apresentam muitas resistências para preencher o guia-diagnóstico. $\mathrm{Na}$ realidade, eles respondem o quadro-diagnóstico e fazem suas considerações na oralidade, nas reuniões de planejamento. Os professores alegam que o tempo deles já é muito comprometido e que a correção deveria ser feita por outra pessoa.

Alguns professores se opuseram a preencher o quadro-diagnóstico completamente, devido ao cansaço e dor da visão.

Durante o período de implementação da política e na busca de sua adequação às escolas, algumas das sugestões encaminhadas ao projeto resultaram em efetivo redesenho de processos e materiais, como o aumento da largura das linhas do quadro-diagnóstico ${ }^{17}$. Outras sugestões foram prejudiciais aos objetivos da Avaliação da Aprendizagem, não tendo sido, portanto, acatadas.

Como visto na Tabela 1, a maior concentração de relatos da categoria voltou-se para questões de falta de material ${ }^{18}$. A inadequação da disponibilidade de material da Avaliação da Aprendizagem para as escolas, indicador que recebeu a maior freqüência de relatos, foi confirmada pela equipe do projeto e esteve relacionada a problemas de distribuição e banco de dados para embalagem que, devido às exigências dos processos licitatórios, era baseado no Censo Escolar do ano anterior, provocando discrepâncias entre esse cenário e a matrícula real.

Esse breve registro sobre a categoria Inadequação de Recursos permite visualizar várias razões pelas quais as escolas poderiam criar estratégias de enfrentamento, enquanto padrões de prática, alterando, desse modo, o formato da Avaliação da Aprendizagem. Da mesma maneira, condições de conflito favoreceriam essas alterações, como pode ser visto a seguir.

\section{Percepção de conflitos}

Conflitos entre diversas políticas, especialmente em um contexto onde duas redes públicas estão envolvidas em vários projetos com graus diversos de articulação, podem ser esperados. Da mesma maneira, podem

17 Para maiores esclarecimentos sobre o redesenho de características da avaliação, ver Bahia $(2003,2004)$.

18 Em estudo posterior, é interessante que se aprofunde o conhecimento da categoria Inadequação de Recursos, especialmente para a rede estadual. Considerada como a "rede mais rica", com recursos provenientes do Banco Mundial no período estudado, e com repasses feitos para as escolas mediante aprovação do PDE, era de esperar que os relatos de inadequação de recursos fossem menos freqüentes que na rede municipal. Isso não ocorreu em quatro de seis indicadores. 
aflorar tensões entre os objetivos de uma determinada política e aqueles da organização escolar ou ainda entre os objetivos da política e os valores individuais de professores e gestores. Esses conflitos são tratados, no modelo de Lipsky, como elementos que contribuem para a ambigüidade de objetivos gerais da agência burocrática, o que torna o trabalho estressante e o ambiente propício para a instalação das estratégias de enfrentamento. No contexto da Avaliação, foram considerados três diferentes indicadores: conflito da Avaliação da Aprendizagem com outras políticas implementadas na/pela escola; conflito da Avaliação da Aprendizagem com os objetivos organizacionais da unidade escolar; e conflito da Avaliação da Aprendizagem com os objetivos individuais dos professores.

Embora o objetivo das reformas seja obter a mudança das escolas, não houve uma clara articulação do papel formal do órgão central no fortalecimento da capacidade local, na experiência da Bahia (como visto também por Walker, 2004). Com isso, esperou-se que as escolas demonstrassem certo estresse organizacional ao ter que coordenar as demandas do programa estadual com as outras solicitações das secretarias da educação e suas representações regionais. Entretanto, a falta de articulação observada entre instâncias não encontrou relato correspondente por parte das escolas. A percepção de conflito da Avaliação da Aprendizagem com outras políticas foi identificada em apenas 6,25\% das escolas estaduais e $8,40 \%$ das municipais.

A maior freqüência de relatos foi agrupada sob o indicador que levantou conflito da avaliação externa com os procedimentos e objetivos da própria escola. Nesse caso, mais de $50 \%$ das escolas municipais e quase $40 \%$ das estaduais fizeram algum registro, observado através de três diferentes linhas de argumentação: 1) a escola expressa necessidade de uso da Avaliação da Aprendizagem para outros objetivos que não aqueles postos pelos seus formuladores; 2) a escola percebe inadequação entre a abordagem pedagógica escolhida por ela e/ou seu município e o formato da Avaliação Externa; e 3) a escola identifica choque entre os procedimentos e as rotinas da avaliação externa e seus processos internos.

$\mathrm{O}$ indicador sobre conflitos entre a Avaliação da Aprendizagem e os objetivos individuais de professores referiu-se a registros de indivíduos (que não foram apresentados como conflitos da comunidade escolar ou mesmo de consenso entre os professores) e apresentou um porcentual de relato de $9,35 \%$ na rede estadual e $21,37 \%$ na municipal. Esse indicador levantou uma grande variedade de argumentos como: "professores não gostam e não têm paciência para fazer os cálculos" (do quadro-diagnóstico) ou "a Avaliação da Aprendizagem é um instrumento que não avalia o processo educacional no seu dia-a-dia". Mesmo não compartilhados pelo 
grupo, foi importante considerar, para os indivíduos em conflito, a possibilidade de criação de padrões de prática que o amenizassem, com impacto na implementação da política de avaliação.

Para finalizar a descrição sobre as condições de trabalho percebidas por professores e diretores, relatadas nos Relatórios do Diretor de 2002 e 2003, a subseção a seguir trata da categoria Alienação.

\section{Alienação}

Última das três categorias da dimensão Condições de Trabalho, a alienação foi originalmente discutida por Lipsky (1980) como estratégia de enfrentamento. Entretanto, neste trabalho ela foi considerada como condição de trabalho por entender-se que configura um traço da cultura da escola. Essa categoria está relacionada à imputação a outros - externos - a responsabilidade a respeito de um fato que poderia ser resolvido internamente pelos burocratas de linha de frente ou, pelo menos, sobre o qual deveriam agir mais diretamente. Em geral, ao fazê-lo, eximem-se da responsabilidade sobre esse fato, contribuindo para a formatação das condições de trabalho. O mesmo ocorre nas escolas. No contexto dessa pesquisa, a Alienação foi observada por meio de três indicadores: 1) responsabilização das características sócio-familiares do aluno e/ou de outros atores externos pela dificuldade de trabalho e baixo desempenho apresentado pelos alunos e escola; 2) perda de controle na escola; e 3) percepção segmentada do processo de aprendizagem do aluno. Os três indicadores dão, em conjunto, uma noção de como a escola enxerga a sua clientela e o seu comportamento diante dela.

Tais indicadores, porcentualmente, tiveram resultados próximos quando sistematizados por rede. Dentre eles, o mais freqüente foi aquele que tratou da responsabilização do aluno, de sua família ou de outros atores externos pelos maus resultados escolares, com um porcentual próximo a $40 \%$ de pelo menos um relato das escolas durante o período investigado, nas duas redes. Esse indicador agrupou as escolas que perceberam a impossibilidade de escolha do aluno ideal (ou da ajuda ideal) como obstáculo para a execução do seu planejamento e para a recompensa dos seus - normalmente grandes - esforços. Dentre os relatos que imputaram aos atores "externos" a dificuldade em se obter uma educação de qualidade, três diferentes linhas de argumentação podem ser destacadas: a primeira reclama do desinteresse dos pais pela educação de seus filhos; a segunda culpa o aluno, que não tem respaldo ou não sofre pressão adequada de sua família e que não reage às questões de qualidade; e a terceira responsabiliza a própria política de Avaliação da Aprendizagem, 
por ter sido delineada em um nível de expectativa de desempenho superior àquele possível para o perfil do aluno ("fraco e carente") de escolas públicas. As três linhas têm em comum o fato de a escola não perceber o seu papel fundamental na busca por um melhor serviço educacional.

Quanto à perda de controle nas escolas, pelos relatos percebeu-se que $12,5 \%$ das escolas estaduais e $15,3 \%$ das municipais lavam suas mãos diante da reação dos alunos, que poderia ser conduzida para um melhor aproveitamento das ofertas escolares. Esse indicador também informou sobre a relação do diretor da escola (responsável pelo preenchimento do Relatório do Diretor) com seu corpo docente. Em alguns casos, observou-se que o diretor usou o relatório para se queixar dos professores, numa transferência de suas responsabilidades para o Projeto de Avaliação Externa ou para as secretarias.

$\mathrm{O}$ terceiro indicador tratou sobre a percepção segmentada do processo de aprendizagem do aluno, agrupando relatos nos quais as escolas atribuíram os percalços da aprendizagem a falhas nas séries anteriores. Desse modo, o professor da série atual não pode ser responsabilizado pelos problemas identificados em sua turma. Para a amostra estudada, esse indicador não foi muito freqüente, com um porcentual de escolas inferior a $7 \%$ nas duas redes.

A análise dos Relatórios do Diretor permitiu observar que, para muitas escolas, a solução da qualidade da educação virá quando forem mudados os seus alunos. Em um contexto de reforma através do fortalecimento da gestão escolar e local, esse talvez seja o ponto mais importante para capacitação dos gestores: a possibilidade de uma abordagem de trabalho que atenda à clientela existente, em lugar do desejo por uma clientela ideal para atender a um padrão de planejamento adotado pela escola.

Concluído o levantamento sobre as percepções das escolas acerca das condições de trabalho relacionadas às categorias Inadequação de Recursos, Percepção de Conflitos e Alienação, a pesquisa se concentrou nos relatos das práticas adotadas por elas durante a implementação da Avaliação da Aprendizagem. Neste artigo, optou-se por apresentar os padrões de prática que foram associados, mediana ou fortemente (Gamma > 0,50), às condições de trabalho, como pode ser lido na seção a seguir.

\subsection{Padrões de Prática Observados e sua Associação com as Condições de Trabalho}

O modelo de pesquisa utilizado pressupõe que, dadas certas condições de trabalho, os implementadores adotam padrões de prática que 
lhes permitem acomodar uma nova política pública na sua rotina de tarefas o que, em última análise, lhes possibilita a sobrevivência. Ao adaptar essa política, nem sempre a favor dos objetivos dos seus formuladores, os implementadores podem dar-lhe um formato diferente, transformando-a. Para fins desta pesquisa, só foram levantados, então, os padrões de prática que, de alguma maneira, poderiam vir a alterar o desenho original da Avaliação da Aprendizagem. O levantamento dos padrões de prática foi feito a partir de quatro categorias: Racionamento, Simplificação, Diferenciação e Conformação, verificadas por meio de 16 indicadores. Das 48 associações entre as 3 categorias Condições de Trabalho e os 16 indicadores de prática, apenas 8 apresentaram comportamento de mediano a forte (Gamma > $0,50)$, ao nível de significância de 0,05 . A seguir são comentadas as relações encontradas.

\section{Práticas de racionamento e as condições de trabalho}

Como estratégia para lidar principalmente com a inadequação recursos, Lipsky apresenta práticas de racionamento, utilizadas de maneira a economizar recursos ou concentrar seu uso em ações que tenham mais chance de atingir os objetivos da agência burocrática. Uma das formas freqüentemente utilizada é a imposição de um custo pelo serviço, mesmo que psicológico, que leve à redução da procura. Outra forma é prestar serviços diferenciados a clientes diferentes, seja pela escolha daqueles que estejam mais propensos à resolução dos problemas (creaming) seja pelo julgamento pessoal.

No contexto da Avaliação da Aprendizagem, as práticas de racionamento foram levantadas por meio de três diferentes indicadores: as estratégias para maximização dos recursos encaminhados pela Avaliação da Aprendizagem; a opção por aplicar provas a um grupo de alunos em detrimento de outros, como forma de lidar com a escassez de material; e o racionamento do tempo na escola, com alteração ou cancelamento dos cronogramas sugeridos de aplicação de provas (externas) para favorecimento de atividades escolares internas.

Como esperado, a maximização do uso de materiais da avaliação e a escolha de alunos e turmas em detrimento de outros colegas tiveram uma associação muito forte com a inadequação de recursos como condição de trabalho. É interessante perceber, inclusive, que a segunda foi ainda mais forte que a primeira, indicando uma possível correção desse padrão, caso os materiais sejam supridos, de maneira adequada, em um próximo delineamento. 
Essas mesmas práticas também apresentaram associação, ainda que mediana, com a categoria Percepção de Conflitos. Nesse caso, o indicador com a maior freqüência de relatos esteve relacionado à percepção de conflitos entre a Avaliação e os objetivos da organização. Uma hipótese a pesquisar pode tentar relacionar a necessidade de lançar mão de práticas de racionamento, pela inadequação de recursos, com os distúrbios que esse esforço cause ao planejamento e conseqüentemente ao atingimento dos objetivos da organização.

Já o indicador sobre adequação ou cancelamento de cronograma sugerido não apresentou associação com qualquer das condições de trabalho, embora fosse esperado que tivesse uma relação forte com a percepção de conflitos. Com um $\gamma=0,452$, mediano a fraco, talvez não tenha sido significativo pelo pouco número de registros levantados.

\section{Práticas de simplificação e as condições de trabalho}

Em educação, várias estratégias de enfrentamento podem ser categorizadas como práticas de simplificação (de processos e/ou de demandas), dentre outras, por considerar uma parte como o todo. É o caso, por exemplo, do professor que transforma o livro didático em currículo para facilitar seu planejamento das aulas, garantindo uma linha estruturada de ação, em especial naquelas escolas sem projeto pedagógico próprio e sem coordenação pedagógica, ainda que reduza bastante as possibilidades de aprendizagem dos alunos. Por meio da simplificação, o burocrata de linha consegue gerenciar sua carga de atividades e a indefinição de metas das diversas políticas às quais está submetido, melhorando assim suas condições de trabalho.

Para esta pesquisa, a categoria Simplificação foi composta por seis diferentes padrões de prática relacionados a algum tipo de minoração de processos e procedimentos realizados pela escola, pela necessidade (imposta pelos formuladores) de implementação da Avaliação da Aprendizagem. Os indicadores foram: 1) o uso das matrizes de referência como livro ou como atividade didática e 2) o uso das matrizes de referência como currículo, em uma redução preocupante do projeto políticopedagógico da unidade escolar às atividades a serem medidas pelos testes; 3) o treino de alunos para a realização das provas, especialmente pelas escolas que não têm o hábito de lidar com questões fechadas e com questões de múltipla escolha; 4) o tratamento das dificuldades identificadas na turma através de exercícios com a própria prova, sem diversificação das ações de remediação; 5) o encerramento do processo avaliativo na aplicação ou na correção das provas, com o cumprimento da etapa de mensuração e 
exclusão das etapas de análise dos resultados e proposta de trabalho a partir deles; e, finalmente, 6) o relato da troca dos processos avaliativos internos pelos externos, com substituição das avaliações que a escola vinha fazendo pela avaliação externa, no todo ou em parte. Esses padrões de prática tendem a comprometer os objetivos maiores da Avaliação da Aprendizagem: a política passa a ser reduzida à aplicação das provas e à obtenção de resultados que as escolas entendam como favoráveis a elas, independentemente do quanto essa simplificação venha a prejudicar sua proposta pedagógica. Dos seis indicadores, três foram mais freqüentes em 2002 que em 2003, talvez indicando uma acomodação da escola em relação aos procedimentos da Avaliação da Aprendizagem. Foram eles: remediação por meio da própria prova, finalização da avaliação com a correção, e treino de alunos para responder as provas.

Quando relacionados às condições de trabalho, dois indicadores apresentaram associação positiva com a categoria Alienação: o uso de matrizes como material didático e a substituição, parcial ou total, da avaliação praticada pela escola pela avaliação externa. Há uma certa lógica nessas associações, uma vez que as condições relacionadas à Alienação tratam da responsabilização de um agente externo em relação ao que acontece na unidade escolar. Nesse caso, as duas práticas de simplificação dão a esse ator externo a autoridade para determinar as atividades e exercícios em sala, com a adoção das matrizes de referência como base para isso, e para determinar aspectos da sua avaliação interna. Essa tendência se reforça pela ausência de associação entre as práticas de simplificação e a percepção de conflito.

Era esperada a associação entre as práticas de simplificação e a inadequação de recursos como condição de trabalho. Na falta de material da avaliação, de material pedagógico, de docentes preparados e de infraestrutura, o caminho possível encontrado pela escola seria uma das estratégias de simplificação. Entretanto, somente quando foi considerado o treino de alunos para fazer as provas a associação foi perfeita $(\Upsilon=+1)$.

\section{Práticas de diferenciação e as condições de trabalho}

Também como forma de garantir a concretização do trabalho, várias práticas relacionadas por Lipsky (1980) estão ligadas à diferenciação dos clientes-usuários, de modo a garantir sucesso na ação, por exemplo. É o caso de escolas que, para obter escores mais altos em avaliações em larga escala, escolhem os melhores alunos para responder as provas. Dentro dessa categoria, estão relacionadas práticas que revelam conflitos sobre o serviço público realizado de maneira personalizada, em contraste com a 
necessidade de um serviço igual para todos; que revelam a preferência do burocrata por certo tipo de cliente-usuário quando comparado a outros, mesmo quando as normas falam sobre igualdade de tratamento. Lipsky sugere que os servidores públicos obtêm maior gratificação ao interagir com alguns usuários que com outros e têm oportunidade de agir para fazer valer essa escolha. Ao excluírem os clientes-usuários "fora do perfil desejado", contribuem para estabelecer condições de trabalho mais favoráveis ao burocrata e a sua agência.

Na pesquisa realizada, a categoria Diferenciação foi composta por quatro diferentes indicadores: a identificação de "melhores" e "piores" com base nos resultados dos testes; a intervenção do professor durante a aplicação do teste no sentido de ajudar os alunos "mais fracos"; as ações realizadas de modo a favorecer os resultados dos testes em uma dada aplicação (quando se percebe uma quebra intencional de padrão nos procedimentos, no sentido de beneficiar a agência burocrática ou seus membros com resultados considerados mais favoráveis); e o relato do uso de estratégias de separação de alunos para participar dos processos de remediação.

Esperava-se que algumas das práticas de diferenciação estivessem associadas às condições de alienação: supostamente, se a escola não pode escolher o seu aluno (e com ele, as características de família), o professor poderia estabelecer algumas estratégias de favorecimento de uns em relação a outros, exercendo então a sua escolha. Especificamente, esperavase uma associação entre o indicador professor ajuda o "aluno fraco" às condições de alienação. Apesar de apresentar um gamma mediano $(0,528)$, ele não foi significativo a 0,05 . Talvez o número pequeno de registros para esse indicador tenha contribuído para isso, o que merece uma investigação futura.

Da mesma maneira, alguns indicadores da categoria Diferenciação deveriam apresentar associação com a percepção de conflitos, pois algumas escolas manifestaram seu desagrado pelo fato da política tratar igualmente alunos fortes e fracos, o que poderia provocar a implementação de estratégias de compensação. Entretanto, a associação (perfeita, $\Upsilon=1$ ) se deu com a identificação de "melhores e piores". Quando houve um conflito, a escola alterou o objetivo da política como forma de resolvê-lo.

\section{Práticas de conformação e as condições de trabalho}

Única das categorias não adaptadas do modelo de Lipsky (1980), os padrões de prática relacionados à Conformação estiveram ligados a processos de ritualização da Avaliação da Aprendizagem, sem que um uso 
efetivo lhe tivesse sido dado e sem que houvesse internalização de seus procedimentos, como visto em Libório e Costa (2004). Para compor essa categoria, foram utilizados três indicadores: a imitação do discurso oficial pela escola, a necessidade de a escola encaminhar seus resultados para um órgão central ou seu representante, e a constante demanda das escolas para que o órgão central atue como ente de coerção e/ou fonte de apoio, numa certa resistência ao processo de autonomia. Os três indicadores foram utilizados por permitir levantar atitudes da escola que denotam acomodação e passividade, sendo prejudiciais aos objetivos da Avaliação da Aprendizagem: a escola apenas acata e cumpre os procedimentos normalizados, alguns dos sugeridos e raramente propõe a partir deles, nas fases mais abertas da política. Ou ainda, a escola espera que o órgão central resolva as questões diagnosticadas por ela. Dos quatro Padrões de Prática, a variável Conformação é a que fala mais diretamente sobre o não atingimento dos objetivos maiores da política pela dificuldade da escola se posicionar de maneira autônoma.

Todos os três indicadores tiveram freqüência maior em 2002 que em 2003, ainda que o número de relatos de dois deles tenha sido bem superior àqueles observados nas outras três categorias de padrão de prática. Uma hipótese para essa redução dos padrões de conformação em 2003 pode associar o tempo de exposição à avaliação a uma postura mais crítica da escola, à medida que os benefícios tivessem (ou não) sido observados. Assim, em 2002 a escola estaria mais conformada que em 2003.

Por terem obtido as maiores freqüências e por não apresentarem qualquer associação com as condições de trabalho, é interessante ser conduzido um novo estudo para investigar se os indicadores de Conformação podem estar associados a outras condições de trabalho não levantadas neste estudo.

De maneira geral, o número de associações entre os padrões de prática relatados e as condições de trabalho percebidas foi pequeno, não confirmando o modelo de Lipsky. Tal fato pode estar relacionado à baixa freqüência de alguns indicadores na amostra pesquisada. Pode também ser decorrente da escolha das categorias relativas às Condições de Trabalho, que não cobriram questões como autonomia e fortalecimento da gestão, ou mais especificamente outras questões apontadas no contexto da Avaliação da Aprendizagem. Uma outra possibilidade para as poucas associações encontradas entre Condições de Trabalho e Padrões de Prática pode ser a inadequação da coleta de dados, feita por meio de um instrumento normalizado, processado pela equipe central da avaliação, o que levaria as unidades escolares a um discurso padrão. Estudos posteriores sobre essas associações poderão levar em conta outras categorias de Condições de 
Trabalho, aumentar a amostra, utilizar outras formas de coleta de dados (incluindo visitas às escolas) e trazer o foco para a última etapa de implementação (Uso), uma vez que especificamente nela nenhuma associação pode ser feita.

Discutida a associação entre as duas dimensões de estudo, resta a pergunta: afinal, os desvios de implementação da Avaliação da Aprendizagem desfiguraram a política como originalmente formulada? A seção a seguir discute o modelo relatado da política.

\subsection{Os Desvios Observados}

Para apresentação do modelo original proposto para a implementação da política da Avaliação da Aprendizagem, foram utilizadas duas categorizações: os tipos de procedimentos e ações (normalizados, sugeridos e abertos) e as fases de implementação (planejamento; aplicação e correção dos testes, e a discussão e uso dos resultados). Essas mesmas categorias são usadas agora para a síntese dos desvios observados, de modo que se possa configurar o modelo relatado.

\section{Fase de planejamento}

Nessa etapa, o modelo original previa várias possibilidades de interação do planejamento da escola com os materiais e desenho da Avaliação da Aprendizagem, em sua maioria sugeridas ou abertas. A configuração de desvio aconteceu quando as decisões relatadas pela escola foram de encontro aos objetivos da avaliação e/ou lhe trouxeram - à escola - prejuízo político ou pedagógico.

Para essa etapa, os padrões de prática desviantes em relação à política original formulada estiveram ligados a alguns dos indicadores da categoria Simplificação: o fato de as escolas utilizarem as matrizes de referência como livro didático (14 relatos) e/ou como currículo (15 registros) mostrou uma opção, ainda que não muito freqüente, no caminho oposto ao proposto pela Avaliação da Aprendizagem. Isso pode indicar que houve redução do currículo escolar a um processo avaliativo externo, baseado em provas de múltipla escolha, em lugar da sua utilização como referência mínima, comum ao Estado.

Tal fato foi reforçado pelos relatos que informaram treinar os alunos para a resolução das provas (12 relatos), em detrimento do desenvolvimento de competências e habilidades previstas nas matrizes e no currículo, e aqueles que trataram de algum tipo de substituição da avaliação interna pela avaliação externa (16 relatos). Considerando-se 654 
relatórios lidos, o porcentual de relatos encontrados para cada indicador foi relativamente baixo, inferior a $2,5 \%$.

Esse estudo foi realizado com escolas que encaminharam pelo menos um Relatório do Diretor em seis aplicações. Uma próxima pesquisa deve ser conduzida para levantar o comportamento das escolas - dos mesmos municípios e de outros - que nunca tenham enviado relatórios. De acordo com dados do Projeto de Avaliação Externa, o porcentual de não encaminhamento de relatórios foi superior a $40 \%$, podendo ser ainda maior na terceira unidade. Assim, a não-utilização dos materiais da Avaliação da Aprendizagem como insumo para o planejamento seria configurada como um dos maiores desvios do desenho original da política, quando considerada toda a população envolvida por ela.

\section{Fase de aplicação e correção}

Nessa etapa, cuja maioria dos procedimentos pode ser caracterizada como normalizada, de maneira geral, não houve muitos desvios em relação ao padrão proposto. As escolas informaram não ter tido problemas em seguir a orientação dos manuais e as ocorrências de aplicação estiveram, em sua grande maioria, ligadas a erros de gabarito (impressão de manuais) e falta de provas. Os indicadores de desvio alocados nessa fase são aqueles que tratam de práticas de racionamento, e outros dois relacionados com as práticas de diferenciação, como pode ser visto a seguir.

As estratégias de maximização do uso de materiais da avaliação, observadas em 42 relatos, não chegaram a desviar o desenho original, tendo sido configuradas como uma série de providências tomadas pelas escolas para resolver falta (ou mesmo excesso) de material de aplicação. Muitas vezes, as unidades seguiram sugestões oferecidas pelo próprio Projeto de Avaliação Externa. Algumas escolas, entretanto, optaram por privilegiar alunos e turmas em detrimento de outras (41 relatos em 654 relatórios, 6,3\%), com quebra grave do padrão de aplicação, com conseqüências para a validade dos dados nas turmas onde houve seleção de alunos. Nas demais, a não aplicação para algumas classes pode ter ocasionado problemas gerais para a escola, pela impossibilidade de obter o diagnóstico de todas as turmas e pela discriminação de algumas classes, em especial do turno vespertino.

Quanto às práticas de racionamento envolvendo adequação de cronograma, apenas uma escola reportou a aplicação de provas antes do final da unidade, tendo quebrado o padrão. Os doze outros relatos, apesar de referirem a não-adoção do cronograma sugerido pelo projeto, não implicaram desvio da política, pois as datas foram apenas sugeridas, 
enquanto o período (imediatamente após a conclusão da unidade) tinha sido normalizado.

Além dos indicadores de racionamento mencionados anteriormente, duas práticas de diferenciação resultaram em desvio para o desenho original, ainda que não freqüente, nessa etapa de aplicação: a intervenção do professor para ajudar alunos que ele considerou "fracos" (8 relatos) e o controle da situação de aplicação para obter resultados melhores (10 relatos).

\section{Fase de discussão e uso dos resultados}

A etapa onde os desvios foram mais freqüentes foi aquela posterior ao preenchimento do quadro-diagnóstico, que implicava análise dos resultados e uso, especialmente por ter uma série de atividades e procedimentos em aberto. Vários indicadores de simplificação e diferenciação e todos os indicadores de conformação têm relação com essa fase da implementação.

Entre os padrões de prática que afetaram o desenho original da política estão o encerramento dos trabalhos com a correção das provas (63 relatos), o que transformou a avaliação em mensuração, apenas; a proposta de trabalho de remediação com base nas provas (31 relatos), sem que houvesse um replanejamento de cursos ou adequação de abordagens, apenas atividades com as provas; e a identificação de "melhores e piores" por meio de uma ferramenta que não se prestava a tal fim (6 relatos).

Sem necessariamente configurar um desvio no desenho original da política de Avaliação da Aprendizagem, mas interessante para a discussão a respeito do tratamento customizado $\mathrm{x}$ a necessidade da padronização do serviço público para assegurar sua eficiência, as estratégias de remediação relatadas (26 registros), às vezes, envolveram ações direcionadas a grupos específicos de alunos, em lugar de um trabalho com as turmas inteiras. Essa prática merece uma investigação: como essa discriminação dos alunos é recebida pelo grupo? Como impacta a qualidade educacional?

Uma segunda discussão também pode ser levantada a partir dos dados informados pela escola: o quanto elas foram fortalecidas e o quanto são autônomas. As práticas relacionadas à conformação foram as mais freqüentes, mesmo quando comparadas com aquelas que tratavam de inadequação de recursos, como racionamento. Essas práticas denotaram uma necessidade de a escola prestar contas e, ao mesmo tempo, contar com a supervisão de um órgão central. Muitas vezes, ficou também demonstrada uma incapacidade de a escola decidir sobre as ações que pudessem resultar na melhoria da qualidade da educação que oferece. Sem 
a participação da escola nessa fase, a avaliação perde a lógica de implementação.

Da leitura de 654 relatórios, apenas 13 apresentaram uma demanda para que o órgão central assumisse, parcial ou totalmente, o planejamento e/ou as decisões sobre o que fazer a partir do resultado; 65 encaminharam os resultados para o Projeto de Avaliação Externa, com várias demandas para que o projeto se posicionasse e sugerisse ações de remediação. Por fim, e mais preocupante, foram os 173 relatos de imitação do discurso oficial ou ausência de posicionamento da escola, especialmente por que a etapa de uso dos resultados foi aquela onde alguns dos procedimentos foram sugeridos, mas, na sua maioria, estavam em aberto. Nesses casos $(26,45 \%$ do total relatado), as escolas cumpriram os procedimentos colocados nos manuais, mas, por intermédio dos seus relatórios, não foi possível identificar as medidas tomadas para melhorar a qualidade da educação. Os desvios de implementação da política de Avaliação da Aprendizagem, nesse último grupo, referiram-se ao não-cumprimento dos objetivos para os quais ela foi formulada.

\section{CONSIDERAÇÕES FINAIS}

Este artigo teve como objetivo apresentar uma síntese da investigação realizada sobre a implementação de uma política pública de avaliação educacional do Ensino Fundamental, no Estado da Bahia. Nesta pesquisa, buscou-se identificar aspectos relacionados ao atendimento dos procedimentos e padrões definidos pelos formuladores da política e buscar associações entre os desvios de padrão observados e a percepção das condições de trabalho por professores e diretores envolvidos.

No decorrer do texto, percebese que, para as escolas pesquisadas, a implementação relatada da Avaliação da Aprendizagem acompanhou os procedimentos normalizados pelo Projeto de Avaliação Externa, na etapa relacionada à aplicação e correção dos instrumentos. Os casos de racionamento que desviaram a política como originalmente formulada estiveram associados à inadequação do número de provas e materiais de aplicação, o que pode vir a ser corrigido pela instância política ou técnica em propostas futuras, evitando, portanto, que esse tipo de problema se repita. Os maiores desvios na política de Avaliação da Aprendizagem estiveram relacionados à ausência de posicionamento das escolas para aquelas atividades ou procedimentos sugeridos ou abertos.

Merece atenção, em especial, o uso feito do processo e produtos da Avaliação da Aprendizagem. É preocupante a falta de posicionamento da 
unidade escolar, por meio da imitação do discurso oficial $(26,45 \%$ dos relatos) ou pela necessidade de encaminhamento dos resultados aos órgãos centrais $(9,93 \%$ dos relatos). Além disso, foram identificados 63 relatos nos quais a avaliação foi encerrada com a aplicação de provas, sem que houvesse registro de qualquer decisão ou atividade decorrente da análise dos resultados. Foi também significativa a queda de freqüência no envio do Relatório do Diretor ao Projeto de Avaliação Externa, sempre maior na terceira unidade letiva, e maior em 2003 quando comparada à de 2002.

Com base nessa experiência, três reflexões podem ser feitas no sentido de contribuir com novos delineamentos de avaliação em larga escala:

1) Sem ser uma ferramenta de controle, a política de Avaliação da Aprendizagem se propôs a facilitar os processos de planejamento e diagnóstico da escola, fundamentada em uma referência estadual. De alguma maneira, essa experiência, na Bahia, implantou uma vertente de avaliação dissociada de processos de regulação. Infelizmente, a etapa relacionada ao uso dos resultados se mostrou a mais fragilizada, como aconteceu com outros modelos de avaliação (Castro, 2005; Heyneman, 2005). Além das questões pontuadas no texto, sobre possíveis deficiências nesse estudo, outra hipótese merece atenção para uma futura investigação: o fortalecimento da gestão escolar ainda não está consolidado e a escola tem dificuldades de propor ações sem a orientação direta do órgão central. No caso estudado, mesmo que os procedimentos normalizados tenham, de acordo com os relatos das escolas, sido seguidos (ainda que paire a dúvida se de maneira ritualizada), as atividades sugeridas ou abertas nem sempre se concretizaram. Esse ponto é crucial na decisão sobre adotar ou não uma política de avaliação externa e sobre sua articulação com o contexto no qual ela vai ser implementada, uma vez que os mesmos recursos podem ser aplicados em outras políticas que talvez provoquem maior impacto na escola.

2) A decisão de entregar a implementação da avaliação àqueles que estavam sendo avaliados foi resultante do conflito entre a necessidade de monitoramento e feedback (censitário) x seus altos custos. A questão assume caráter interessante pelo aparente contra-senso, quando a política implementada é justamente aquela que monitoraria o implementador. Vários questionamentos foram feitos a respeito da possibilidade de uma real implementação da avaliação nessas bases. Por um lado, esperavam-se desvios de implementação em relação a burlas e fraudes nas aplicações, que levassem a um resultado mais "favorável" nas provas. Por outro, e em defesa da utilização de uma abordagem escola-dependente também para as políticas de avaliação, estiveram formuladores que privilegiaram a questão 
dos custos. Nesse lado de defesa estavam também os formuladores que, em um contexto de autonomia e descentralização, entenderam que as escolas independentemente da escassez de recursos - deveriam ser parceiras dos governos para atingir o objetivo maior da educação pública: educação de qualidade para todos.

A tendência observada na amostra pesquisada, ainda que não representativa, parece apontar para a possibilidade de uso do implementador para esse tipo de política. Caso os relatos encaminhados pelas escolas tenham correspondido à realidade, os procedimentos normalizados foram aqueles mais próximos à proposta formulada para a Avaliação da Aprendizagem. Vale ressaltar que essa experiência baiana trata de um modelo low stakes de avaliação e esse padrão pode não ser observado em políticas high stakes.

3) Esta reflexão é decorrente de um aspecto mencionado várias vezes pelas escolas durante a investigação: o envolvimento de pais na educação de seus filhos. Quando da formulação de políticas de avaliação, como aconteceu na Bahia, tem-se a expectativa de que, de posse dos resultados, os pais possam exercer algum tipo de pressão diretamente sobre as escolas, de modo a garantir que seus filhos tenham a melhor educação possível, muitas vezes entendida como escores mais altos em avaliações em larga escala.

A orientação encaminhada às escolas, no caso da Avaliação da Aprendizagem, foi para que os dirigentes e o corpo docente envolvessem os pais nas discussões dos diagnósticos obtidos e, principalmente, na implementação de soluções. Em resposta, a expectativa colocada por essas escolas foi de que os pais poderiam ajudar no apoio às atividades extraescolares, propostas como caminhos de remediação, como o acompanhamento da realização das tarefas de casa, o incentivo a pesquisas extra-muros, o favorecimento de um maior tempo do aluno na escola, dentre várias possibilidades. Também poderiam ser úteis trabalhando como voluntários em projetos de reforço escolar, leitura, etc. As escolas, portanto, não viram os pais como um elemento de pressão (como esperam os governos, de maneira geral) e sim como ajuda.

Entretanto, especialmente na terceira unidade de 2002, os relatos das escolas apontaram para a dificuldade desse relacionamento, ainda que muitas tivessem tentado essa parceria. De 163 escolas, apenas uma fez um relato mais positivo sobre a presença dos pais na educação de seus filhos. Além de não serem o apoio esperado, os relatos das escolas reforçam o ponto de vista de Lipsky (1980), para quem o cliente-usuário não é um ponto de referência para o servidor público, não se constituindo assim como elemento de pressão. 
Por essa razão, o envolvimento dos pais na educação de seus filhos merece análise mais criteriosa quando da criação de novas políticas públicas que tentem se valer do cliente-usuário como um controle ou como fonte de pressão pela melhoria da qualidade. Essa análise poderá apontar, entre outras opções, para a necessidade de campanhas de sensibilização e conscientização mais direcionadas, que alertem esse segmento da importância de sua participação.

Reconhecendo a necessidade de aprofundamento dessa investigação, espera-se que este estudo tenha esclarecido uma série de aspectos e características de implementação de uma política pública na área de avaliação educacional em larga escala, não regulatória, e que, ao fazê-lo, incentive os formuladores de novas políticas a buscar inovar seus modelos e concentrar esforços no uso dos resultados da avaliação. Somente através de um uso responsável, que implique a melhoria da qualidade educacional, os custos e os esforços da avaliação se justificam.

\section{REFERÊNCIAS BIBLIOGRÁFICAS}

ALGARTE, Roberto A. Competência Política da Escola Pública. Ensaio: avaliação e políticas públicas em educação. Rio de Janeiro, v.9, n. 30, p. 2742, jan./mar. 2001.

BAHIA. Educar para vencer: o ensino público do novo século. Folder promocional do programa. Salvador: Governo da Bahia; Secretaria da Educação, 1999.

Construindo a escola Terra Bahia: proposta de educação básica. Salvador: Governo da Bahia; Secretária da Educação/SUPEN, 2000.

Projeto de Avaliação Externa. Avaliação da Aprendizagem: participação e contribuições das escolas em 2002. Salvador: SEC/UFBAISP/FAPEX, 2003. Disponível em: <http://www.aval.ufba.br>. Acesso em: set. 2004.

Avaliação da Aprendizagem: participação e contribuições das escolas em 2003. Salvador: SEC/UFBA-ISP/FAPEX, 2004. Disponível em <http://www.aval.ufba.br>. Acesso em: set. 2004.

Avaliação de Desempenho do Ensino Fundamental do Estado da Bahia

- 2001. Salvador: SEC/UFBA-ISP/FAPEX, 2003. Disponível em: <http://www.aval.ufba.br>. Acesso em: set. 2004. 
BARROSO, João. Gestão local da educação: entre o Estado e o mercado, a responsabilização coletiva. In: MACHADO, L. M.; FERREIRA, N. S. C (org.). Política e Gestão da Educação: dois olhares. Rio de Janeiro: DP\&A, 2002, p. 199-212.

Regulação e desregulação nas políticas educativas: tendências emergentes em estudos de educação comparada. In: BARROSO, João (org.). A escola pública: regulação, desregulação, privatização. Porto: Edições Asa, 2003, cap. 1, p. 19-48.

BONAMINO, Alicia; FRANCO, Creso; BESSA, Nicia (orgs.). Avaliação da Educação Básica: pesquisa e gestão. Rio de Janeiro: Ed. PUC-Rio; São Paulo: Loyola, 2004.

BOORSMA, Peter B. La gerencia pública moderna en la teoria y la práctica. Especial referencia a los Países Bajos. Reforma y Democracia. Caracas, n. 8, maio 1997. Disponível em: <http://www.clad.org.ve/rev08/0029900.pdf>. Acesso em: 16 dez. 2003.

BRASIL. Instituto Nacional de Estudos e Pesquisas Educacionais Anísio Teixeira. Curso de Aperfeiçoamento para Professores de 1a a 4a Série do Ensino Fundamental: uma avaliação. Salvador: IAT/SEC, 1998.

CASTRO, Cláudio de Moura. Avaliação não é para amadores. In: SOUZA, Alberto de Mello (org.). Dimensões da Avaliação Educacional. Petrópolis, RJ: Vozes, 2005. p. 246-258.

CASTRO, Maria Helena Guimarães de. A Educação para o século XXI: o desafio da qualidade e da equidade. Brasília: Inep, 1999.

CAVALIERE, Ana Maria Villela. Educação integral: uma nova identidade para a escola brasileira? Educação \& Sociedade [online], v. 23, n. 81, p.247270, dez. 2002. Disponível em: <http:/ / www.scielo.br/scielo.php?> Acesso em: 5 jan. 2003.

CORRALES, Javier. Aspectos políticos na implementação das reformas educacionais. Programa de Promoção da Reforma Educativa na América Latina e Caribe - PREAL. n. 14, 2000. Disponível em: <http://www.preal.cl>. Acesso em: 20 jul. 2004.

DYE, Thomas R. Understanding public policy. 8th $^{\text {th }}$. New Jersey-EUA: Prentice Hall, 1995. 
DEPRESBITERIS, Léa. A Avaliação na Educação Básica: Ampliando a Discussão. Estudos em Avaliação Educacional. São Paulo: Fundação Carlos Chagas, n. 24, p. 137-146, jul./ dez. 2001.

GENTILI, Pablo. Neoliberalismo e educação: manual do usuário. In: SILVA, T. S.; GENTILI, P. (org.) Escola S. A.: quem perde e quem ganha no mercado do neoliberalismo. Brasília: CNTE, 1996.

HEYNEMAN, Stephen P. Avaliação da qualidade da educação: lições para o Brasil. In: SOUZA, Alberto de Mello (org.). Dimensões da Avaliação Educacional. Petrópolis, RJ: Vozes, 2005. p. 35-62.

LIBORIO, Helena; COSTA, Jorge Adelino. O Impacto de um programa de avaliação externa no desenvolvimento organizacional de uma escola. Ensaio: avaliação e políticas públicas em educação. Rio de Janeiro, v.12, n. 43, p. 696-710, abr./jun. 2004.

LIMA, Licinio C. Modelos organizacionais de escola: perspectivas analíticas, teorias administrativas e o estudo da acção. In: MACHADO, L. M.; FERREIRA, N. S. C. (org.). Política e Gestão da Educação: dois olhares. Rio de Janeiro: DP\&A, 2002, p. 33-54.

LIPSKY, Michael. Street-level bureaucracy: dilemmas of the individual in public services. New York: Russel Sage Foundation, 1980.

LUCKESI, Cipriano. Avaliação da Aprendizagem Escolar. 10.ed. São Paulo: Cortez, 2000.

MOLINA, Carlos Geraldo. Las reformas educativas em América Latina: hacia uma mayor equidad? INDES Working Paper Series; I-36. Washington, D.C., 2002.

NOGUEIRA, Marco Aurélio. Administrar e dirigir: algumas questões sobre a escola, a educação e a cidadania. In: MACHADO, L. M.; FERREIRA, N. S. C. (org.). Política e Gestão da Educação: dois olhares. Rio de Janeiro: DP\&A, 2002, p. 17-32.

OLIVEIRA, Cleiton. Gestão da educação: União, Estado/Distrito Federal, município e escola. In: MACHADO, L. M.; FERREIRA, N. S. C. (org.). Política e Gestão da Educação: dois olhares. Rio de Janeiro: DP\&A, 2002, p. 6982. 
OLIVEIRA, Lindamir Cardoso Vieira. Cultura escolar: revisando conceitos. RBPAE, v.19, n. 2, p. 291-303, jul./ dez. 2003.

OSBORNE, David. Reinventando o governo. Brasília: MH Comunicações, 1994.

SANDER, Benno. O Estudo da administração da educação na virada do século. In: MACHADO, L. M.; FERREIRA, N. S. C. (org.). Política e Gestão da Educação: dois olhares. Rio de Janeiro: DP\&A, 2002, p. 55-68.

SOUZA, Celina. "Estado do Campo" da pesquisa em políticas públicas no Brasil. Revista Brasileira de Ciências Sociais, v. 18, n. 51, fev. 2003.

Workshop sobre políticas públicas e avaliação. Salvador: Fundação Luis Eduardo Magalhães, dez. 2002. (mimeo.)

SOUSA, Clarilza Prado de. (org.) Avaliação do rendimento escolar. 6.ed. Campinas, SP: Papirus, 1997 (Coleção Magistérios: formação e trabalho pedagógico.)

UNIVERSIDADE FEDERAL DA BAHIA/ISP. Relatório de Conclusão Projeto de Avaliação Externa 1999-2004. Mimeo, 2004.

VIANNA, Heraldo Marelim. Programas de avaliação em larga escala: algumas considerações. Estudos em Avaliação Educacional. São Paulo: Fundação Carlos Chagas, n. 23, p. 93-104, jan./jul. 2001.

WALKER, ELAINE M. The impact of state policies and actions on local implementation efforts: a study of Whole School Reform in New Jersey. Educational Policy, v. 18, n. 2, p. 338-363, May, 2004.

Recebido em: agosto 2006

Aprovado para publicação em: julho 2007 
